\title{
HIGH-TOOL - a strategic assessment tool for evaluating EU transport policies
}

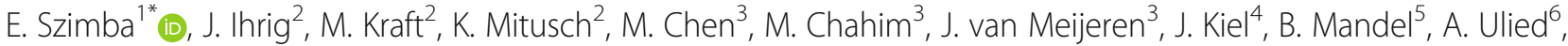 \\ E. Larrea ${ }^{6}$, G. De Ceuster ${ }^{7}$, R. Van Grol ${ }^{8}$, Z. Berki ${ }^{9}$, A. Székely ${ }^{9}$ and R. Smith ${ }^{10}$
}

\footnotetext{
* Correspondence: szimba@kit.edu ${ }^{1}$ Karlsruhe Institute of Technology (KIT), Network Economics, Institute of Economics (ECON), Waldhornstr. 27, Bldg. 01.96, 76131 Karlsruhe, Germany

Full list of author information is available at the end of the article
}

\begin{abstract}
In this paper the strategic transport policy assessment instrument HIGH-TOOL is presented. The model has been developed for the European Commission, allowing policy-makers to identify the most advantageous transport policies and to strategically evaluate the impacts of transport policies on transport, environment and economy.

The main innovation of this policy assessment tool lies in the integration of originally independently functioning models - i.e. passenger and freight demand,

demography, and vehicle stock models, as well as economic, environmental and safety assessment models. With its traffic zones at the regional level of NUTS-2 and its aggregated view on the transport system, the instrument has a relatively lean structure avoiding runtime problems, without losing the spatial dimension. What distinguishes HIGH-TOOL from all other European transport policy assessment instruments: the model is an open source tool, it is freely available and does not require any commercial software to be run. In combination with its modular structure the HIGH-TOOL model can relatively easily be adjusted to other modelling methodologies or data. It can also comparatively easily be made responsive to "new" policies which are not in the scope of the current model version. Thus the HIGHTOOL model lays the foundation for further innovations in the assessment of transport policies and mobility concepts.

Keywords: Assessment tool, Transport policy, Transport demand modelling, Transport model, Impact assessment, European Union
\end{abstract}

\section{Introduction and policy context}

Decisions on transport policy measures proposed by the European Union (EU) as addressed by the White Paper on Transport (European Commission 2011a) have long-term and important impacts on economy, environment and society. Transport policy measures can lock up capital for decades and cause manifold external effects and indirect effects in many sectors - thus, policy measures may have a tremendous scope, especially if proposed at the European level.

Various authors, such as Sieber et al. (2013), Nilsson et al. (2008) or McIntosh et al. (2011), emphasize the increasing importance of impact assessment tools as decision support instruments for policy making, allowing policy-makers to analyze relationships within a complex system and to reach decisions based on quantitative information.

(c) The Author(s). 2018 Open Access This article is distributed under the terms of the Creative Commons Attribution 4.0 International License (http://creativecommons.org/licenses/by/4.0/), which permits unrestricted use, distribution, and reproduction in any medium, provided you give appropriate credit to the original author(s) and the source, provide a link to the Creative Commons license, and indicate if changes were made. 
In this context, the strategic assessment model "HIGH-TOOL" has been developed to compute economic, environmental and social impacts of transport policies, allowing European policy-makers to identify the most advantageous transport policies and to carry out strategic assessments of transport policies. HIGH-TOOL, which stands for "high-level strategic transport model", addresses EU transport policies in the scope of the European Commission's White Paper on Transport. The tool's output indicators are largely aligned with assessment indicators of EU policy documents such as the EU's Impact Assessment Guidelines (European Commission, 2009).

The main objective of the HIGH-TOOL project has been the development of an open strategic transport policy assessment instrument for the European Commission, which is largely based on already existing tools, which has a low runtime and which provides a high level of user-friendliness. Within this setting, the HIGH-TOOL model integrates originally independently functioning models.

This paper provides an overview of structure, modelling approach and application aspects of the HIGH-TOOL model. Thus, the paper has a "synopsis" character, providing an overview perspective rather than a description of the modelling or validation approach at a highly detailed level.

The paper is structured as follows: Chapter 2 provides an overview of general tool features, structure of the model, and of the methodology behind the individual modelling entities (modules). Chapter 4 summarizes the testing and validation approach. Chapter 5 addresses the scope of transport policy measures considered, the approach chosen to operationalize these policies, and presents the "hypernet" conception. Chapter 6 presents a case study. The paper closes with chapter 7, the conclusions.

\section{Model methodology}

Modelling philosophy

Reflecting one of the key goals of the HIGH-TOOL project - i.e. the development of an assessment instrument that is largely based on already existing tools -, the HIGH-TOOL model integrates originally independently functioning models - i.e. passenger and freight demand, demography, and vehicle stock models, as well as economic, environmental and safety assessment models. This requires that already existing European state-of-the-art transport demand and assessment models are integrated by a common platform and are connected to a common database, relying on a common foundation, such as a common business-as-usual scenario, geographical scope, spatial entities, and demand segmentation.

The contents of this chapter are partly based on Szimba et al. (2017), as well as on project reports by Szimba (2016), Mandel et al. (2016), and Van Grol et al. (2016).

\section{General scope}

The HIGH-TOOL model has a global scope. However, the main focus is attached to Europe, and particularly to the Member States of the European Union. The spatial scope is the level of NUTS- $2^{1}$ for all EU Member States (EU28), Norway and Switzerland, NUTS-0 for EU neighboring countries, and country bundles for intercontinental transport. In total 314 modelling zones are considered. 
The tool's timeline are 5-years steps from 2010 to 2050. The year 2010 is the base year of the HIGH-TOOL model. The HIGH-TOOL baseline or business-as-usual scenario is aligned with the EU Reference Scenario 2013 (European Commission 2013). Thus the forecasts of the HIGH-TOOL baseline are largely consistent with those of the EU Reference Scenario 2013.

Passenger demand is differentiated by following modes: air, rail, road (passenger car and powered 2-wheelers), and long-distance coach. The urban demand sub-module additionally considers urban bus, urban tram/metro, cycling and walking. The demand differentiation by trip purpose covers business, private, vacation, and commuting trips. The freight transport is modelled by multi-modal transport chains, considering the transport modes air, rail, road, inland waterways, and maritime transport. The demand is considered for NST-2 commodities (52 commodity groups). The vehicle fleet is distinguished by 60 vehicle types and 17 fuel types.

The HIGH-TOOL model was largely developed in Java, thus ensuring platform independence. The User Interface was programmed as a stand-alone online application based on AngularJS and SailsJS, both free and open source software components programmed in JavaScript. The HIGH-TOOL Database that stores input, output data as well as modelling parameters of all modules, is realized as a PostgreSQL database with PostGIS extension (Kiel et al. 2016b).

\section{Model structure}

The HIGH-TOOL model consists of three main elements: Core modules that represent the modelling framework; the Database that facilitates the exchange of data; and the User Interface for application of the model and providing access to the assessment results. The basic structure follows the natural architecture common for most Decision Support Systems (DSS). The core modules are assembled such that a wide spectrum of specific transport topics can be addressed by the model while minimizing interdependencies in favor of short model runtime. In consequence, the number of core modules was finally condensed to seven and their internal structure was designed to allow for fast processing avoiding loops, while reflecting essential relations consistently. The core modules of the HIGH-TOOL model are constrained to these design features over detailed implementation of complex interdependencies, as the tool is outlined to provide decision support by testing policy scenarios for the European Union on a strategic level before the most promising ones are implemented in more detailed (network-based) models such as TRANSTOOLS or Vaclav.

The core modules are as follows: Demography (DEM), Economy \& Resources (ECR), Passenger Demand (PAD), Freight Demand (FRD), Vehicle Stock (VES), Environment (ENV), and Safety (SAF). In the center of the model are the passenger and freight demand modules (PAD and FRD). Since transport demand is driven (among others) by demographic and economic developments, DEM and ECR provide inputs for the demand modules. Based on transport demand, environmental and safety impacts are computed by ENV and SAF. To estimate economic impacts of transport policies, PAD and FRD provide demand data to ECR. As the composition of the vehicle fleets effects both transport costs and emission factors, VES provides inputs to the demand modules PAD and FRD, as well as to ENV. Figure 1 displays the detailed structure of the model, 


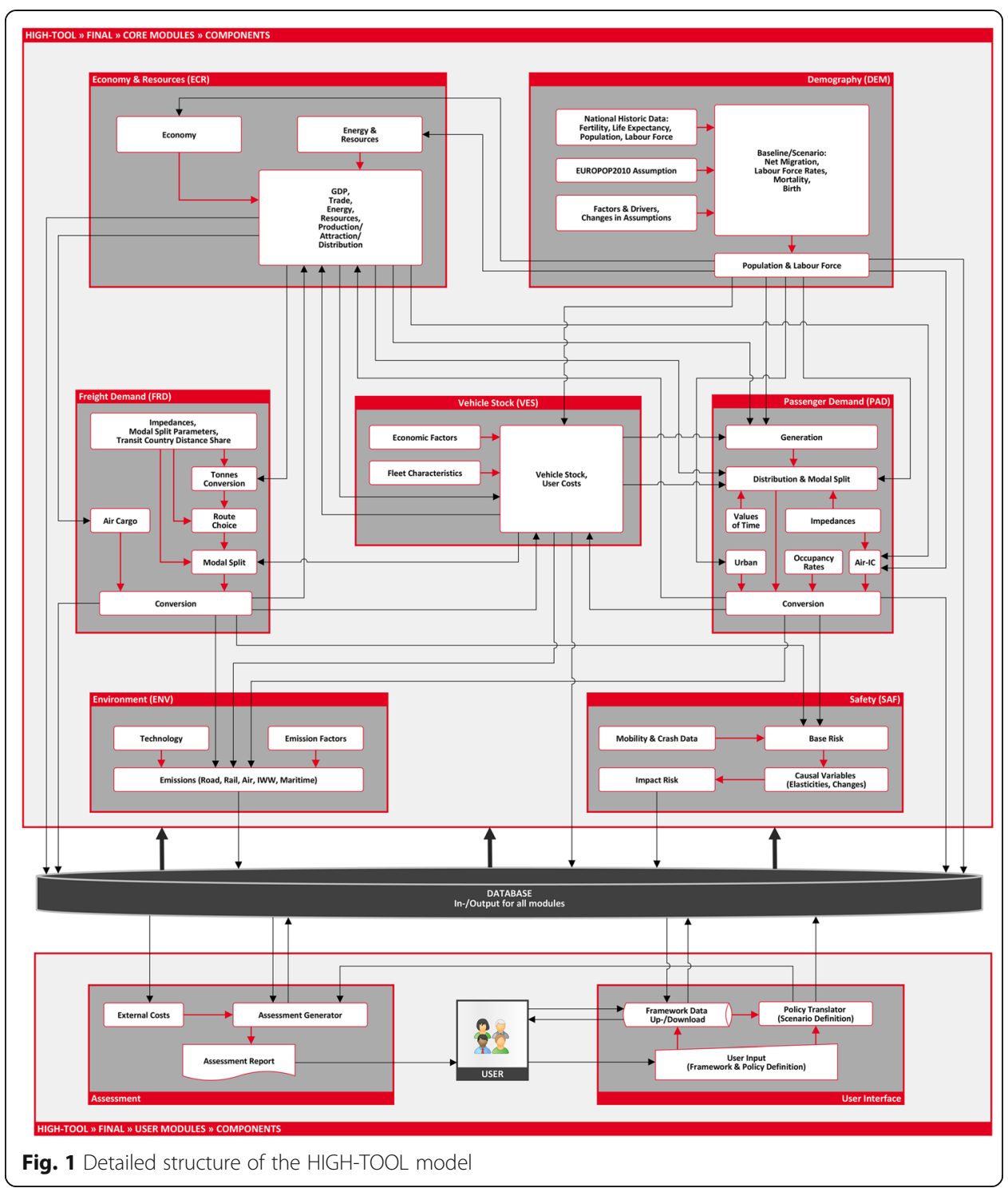

also depicting the structure within the core modules. The model structure is explained in detail, including the variables which are exchanged between the modules, by Mandel et al. (2016). The core modules interact sequentially with each other (see section "Module Interaction").

\section{Demography module}

The Demography module (DEM) calculates the regional population and labor force in the 28 EU Member States as well as in Norway and Switzerland. UN projections (United Nations 2014) are used for other countries worldwide and are adapted to the geographic zoning system used in HIGH-TOOL.

The population and labor force are derived from the Europop assumptions on demographic trends (European Commission 2011b) at country level for the EU 28, Norway and Switzerland. These trends are aligned with the EU Reference Scenario 2013's assumptions concerning fertility rates, life expectancies at birth and net migration 
(European Commission 2013). Net migration is not modelled explicitly; it is taken exogenously from the EU Reference Scenario. The projected population values from the EU Reference Scenario by country are disaggregated to geographic zones based on historical demographic trends concerning population development. This is done by using a demographic model which calculates future population by zone, based upon fertility rates and life expectancies. The population and labor force values from Europop are then disaggregated based upon the results from the demographic model. This allows consistent results with the Europop population trends. Kiel et al. (2016b) and Van Grol et al. (2016) contain a more detailed specification of the demographic model and the calibrated values of the parameters and coefficients.

Regional disaggregation of the population excluding migration is based on the 2010 historical regional distribution. Net migration is regionally distributed using a distribution proxy based on income and employment rate. Labor force is estimated from the labor force percentage defined in the EU Reference Scenario and underlying assumptions.

Being calibrated to the EU Reference Scenario 2013 and the projections by the United Nations (UN), the results of the Demography module are aligned with the expected economic development in Europe. However, the demographic development is an exogenous variable in HIGH-TOOL, i.e. the module is not sensitive to any policy.

Figure 2 provides an overview of the structure of the Demography module.

The Demography module's most relevant data interchanges with other modules are population data at regional scale (NUTS-2), differentiated by age and gender cohort, which are input to ECR, VES and PAD. Furthermore, regional labor force data are provided to ECR and VES.

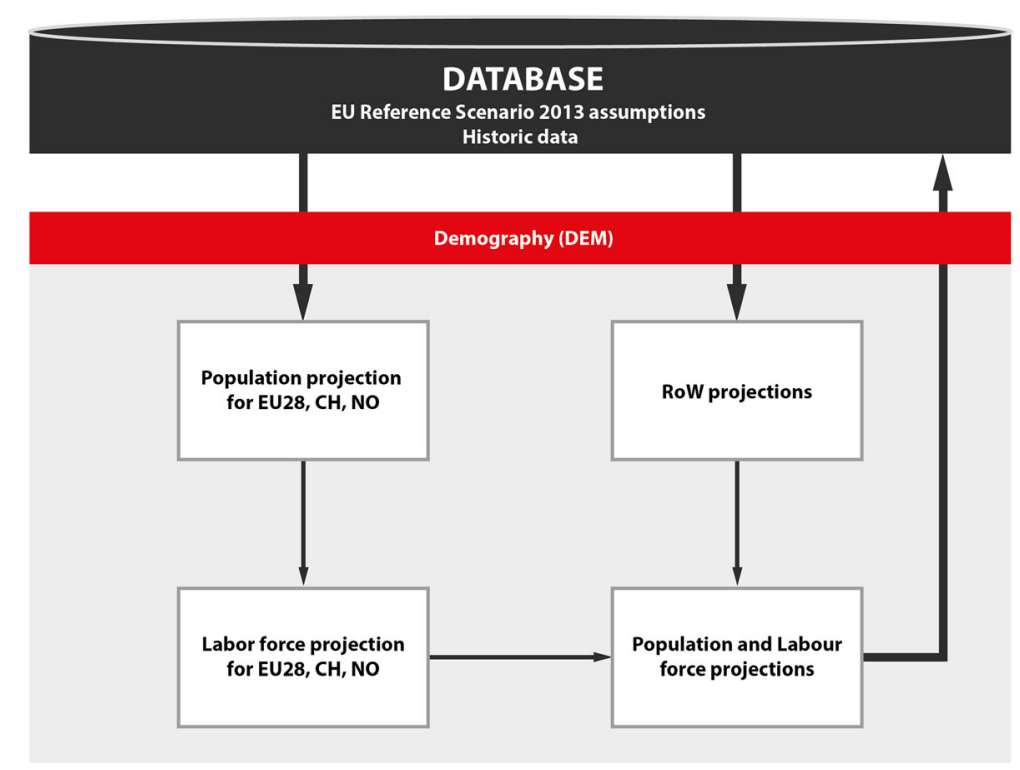

Fig. 2 Structure of the Demography module 


\section{Economy \& Resources Module}

The Economy \& Resources module (ECR) comprises two components: Economy and Resources, as well as of the outputs GDP, Trade, Energy, Resources, and Production/ Distribution (see Fig. 3).

The Economy sub-module estimates total output, capital stock and labor use in the economy, for which the general drivers (Gross Domestic Product (GDP), household income per capita and population) are - for an initial run without any policies - exogenously defined by the EU Reference Scenario 2013 (European Commission 2013). These drivers are disaggregated from country to zone based on ETISplus data (regional GDP, regional population, and labor force). The combined component (GDP, Trade, Energy, Resources, Production/ Distribution) estimates employment, trade, resource consumption, and purchasing power. The resources component calculates environmental indicators (without combustion) using the EXIOBASE database (Wood et al. 2015) for $\mathrm{CO}_{2}, \mathrm{NOx}$, SOx, PM, biomass, fossil fuel use, metal use, mineral use, wood use, and water use.

The methodology chosen for the Economy \& Resources module is driven by a set of sequential algebraic equations, based on the first-order conditions for utility and profit maximization. The Economic module follows the algebraic framework of a (computable) general equilibrium model. The total output per region is generated using a Cobb-Douglas equation using total wages and total value of capital stock by region as inputs. Future trends in terms of growth in Gross Domestic Product and development of sectoral shares in Gross Value Added are obtained from the EU Reference Scenario 2013. The growth paths of economic and environmental indicators (e.g., intermediate inputs, $\mathrm{CO}_{2}$ emissions, water use or wood use) are driven by the total sectoral output trajectory. Moreover, projected demand is calculated as the sum of final demand of

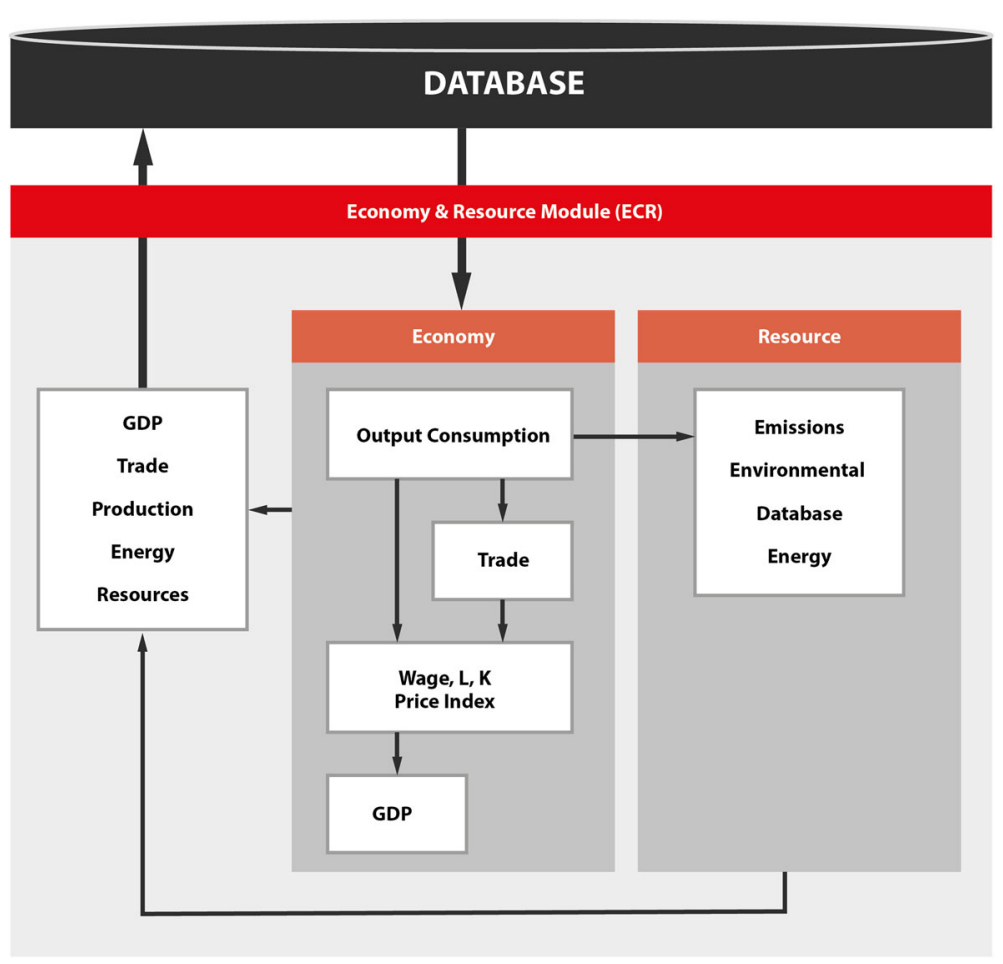

Fig. 3 Structure of the Economy \& Resources module 
households and the intermediate demand of sectors (under the assumption of fixed Leontief technology).

For modelling trade flows the following method is applied: For the base year, trade flows by country pairs in the base year are derived from the ETISplus database. ETISplus estimates NUTS-2 inter-regional trade using national data from Eurostat statistics with its known limitation such as less detailed or missing data at regional level. Subsequently, sectoral Gross Value Added data at NUTS-2 level (source: Eurostat) are applied to scale down the country-level trade to the regional level. This creates different trade shares per commodity for each region. In this way the heterogeneity of each region in a country is incorporated, i.e. not all regions export the same product mix. On the import side, the regional GDP share is applied to disaggregate the trade flows. In order to compute the share of intra-regional trade with respect to outgoing inter-regional trade, we combine RHOMOLO data (see Ivanova et al. 2011) on intra-regional trade (i.e. trade between NUTS-2 regions within in a country) with ETISplus inter-regional trade (i.e. trade between NUTS-2 regions of different countries) for regions where both data is available.

The average commodity share of inter-regional trade is used to estimate the intra-regional trade for the remaining regions. By doing so, we implicitly assume that the freight handling factor (i.e. the frequency of lifts of the tons in the supply chain from the place of production to the place of consumption) for intra-regional trade is at least equal to the inter-regional trade. For intra-regional trade we assume that the share of a commodity is equal to the average exporting share of a commodity to the different regions.

For the assessment of economic impacts of a policy scenario the following effects are captured by the ECR module.

The changes in monetary costs of freight transport (i.e. the cost differences between the policy scenario and the baseline), differentiated by mode and commodity, are translated into changes in consumer prices. The consumer prices include both transport and trade margins as well as consumption taxes and subsidies.

A decrease in transportation cost improves regional accessibility, which has a positive impact on the sector output at the regional level through provision of better access to labor markets and more varieties of intermediate goods.

Next, the projected demand for goods and services in a region are calculated as the sum of the final demand of households and the intermediate demand of sectors. We calculate regional intermediate demand as the sum of intermediate demand over all the sectors located in the region (under the assumption that intermediate goods and services are used in the production according to fixed Leontief technology). The regional intermediate demand is recalculated using the spending on the purchase of new vehicles in each sector and time period, new transport investment in Research and Development (RTD) and new infrastructure investments (these variables drive direct change in intermediate demand due to transport related investments).

Finally, we assume that the household sector is driven by a Cobb-Douglas utility function (see, e.g. Ivanova 2014). Changes in the total costs of passenger transport have an impact on the level of disposable income of the households. Increases in passenger transportation costs reduce the amount of money available for purchasing of other goods and services, affecting also the household sector's consumption of cars. 
Changes in trade are modelled by the change in regional sectoral output between the baseline trajectory and the policy scenario (i.e. growth of sectoral output is applied to exports).

Finally, the (new) Gross Domestic Product is derived at regional level on the basis of the variables calculated above as the sum of the value added of individual sectors plus taxes on final demand.

The ECR module's most relevant input data are regional population and labor force data provided by DEM, transport costs and transport demand by PAD and FRD, as well as vehicle tax revenue and vehicle stock data (purchase costs of new vehicles, vehicle stock by mode and fuel type) by VES. ECR's main output to other modules are regional GDP per capital values for VES, trade flows in monetary values to FRD, and regional GDP, GVA and employment data for PAD.

\section{Vehicle stock module}

The Vehicle Stock module (VES) converts passenger and freight demand to vehicle fleet size, which is disaggregated to vehicle type and vehicle age cohort for calculation of emissions and energy use. Vehicle types include propulsion and fuel technologies, and the module embraces 61 road and 12 non-road vehicle types. The vehicle age cohorts range from 0 to 29 years.

Fleet stock forecasts are provided at country and region for each of the $28 \mathrm{EU}$ Member States and for each period (5-year intervals) up to 2050. The module also delivers forecasts of average fixed (e. g., purchase costs, vehicle technology related costs) and variable costs (e.g., fuel costs, taxes, maintenance/repair costs, insurances, crew costs, cargo handling costs) for each vehicle type, and total tax revenue per country.

Taking into account the transport demand and the vehicle stock in the previous period, as well as the vehicles that survived in current period, the demand for new vehicles and the average mileage per vehicle are calculated.

The logit and the stock dynamic model inside the Vehicle Stock module use the calculated average generalized costs and behavioral aspects to define the shares of the different types of new vehicles entering the market as well as their numbers. This calculation produces the detailed existing vehicle stock in the current period.

The methodology underlying the Vehicle Stock module is aligned with TRACCS (Papadimitrio et al. 2013) and TREMOVE (De Ceuster et al. 2007). The structure of the module is shown by Fig. 4 .

There is no explicit distinction between company cars and private cars, but the effect is implicitly included in the decreasing annual mileage with increasing age, as well as by the different annual mileage for different vehicle types (e.g. higher annual mileage for diesel as these are more likely to be company cars).

The module's most important input data are population data by DEM, GDP per capita data by ECR, as well as demand data (vehicle-km, load factors/ car occupancy rates) by PAD and FRD. The VES module's main outputs to other modules are vehicle tax revenue and vehicle stock data (purchase costs of new vehicles, vehicle stock by mode and fuel type) to ECR, vehicle stock by mode, fuel type and vehicle technology to ENV, as well as generalized fixed and variable costs per vehicle-km (differentiated by mode and fuel type) to PAD and FRD. 


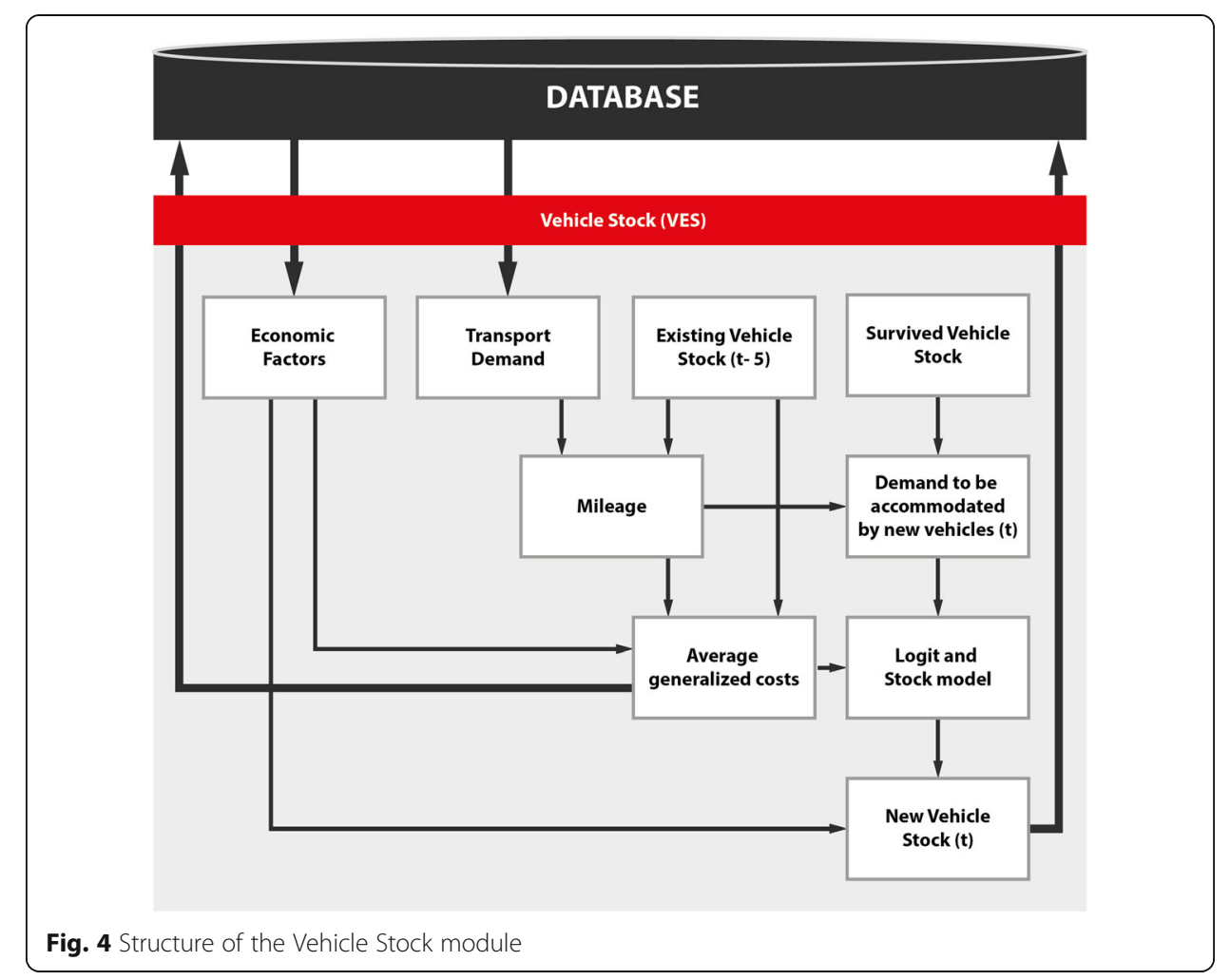

\section{Passenger demand module}

The core Passenger Demand (PAD) module computes the number of passenger trips per year by transport mode for each origin/destination (O/D) relation at NUTS-2 level. It distinguishes the four main transport modes, rail, road, air, coach. PAD largely follows the classical four-step approach in transport demand modelling of generation, distribution, modal split and assignment (Ortúzar and Willumsen 2011). However, instead of the assignment step, the module translates the number of trips into transport performance indicators by the conversion step.

The methodology of PAD is outlined by Fig. 5. It relies on a rather complex mathematical framework encompassing 44 equations that are described in detail by Van Grol et al. (2016). Considerably simplified, the computation of the O/D trip matrices $\left(T_{i j m}\right)$ carried out by the generation, distribution and the modal split models can be outlined as follows:

$$
T_{i j m}=T_{i} \cdot \frac{A_{i j}}{\sum_{j} A_{i j}} \cdot S_{i j m}
$$

where:

$T_{i j m}$ Number of trips per year from origin $i$ to destination $j$ by transport mode $m$

$T_{i}$ Generated passenger trips in zone $i$

$A_{i j}$ Accessibility of opportunities in destination $j$ from origin $i$

$S_{i j m}$ Market share of transport mode $m$ of those trips from zone $i$ to zone $j$.

In the first step, the trip demand $T_{i}$ is generated for each origin based on the population and specific trip rate factors. These trip rate factors are distinguished by year and 


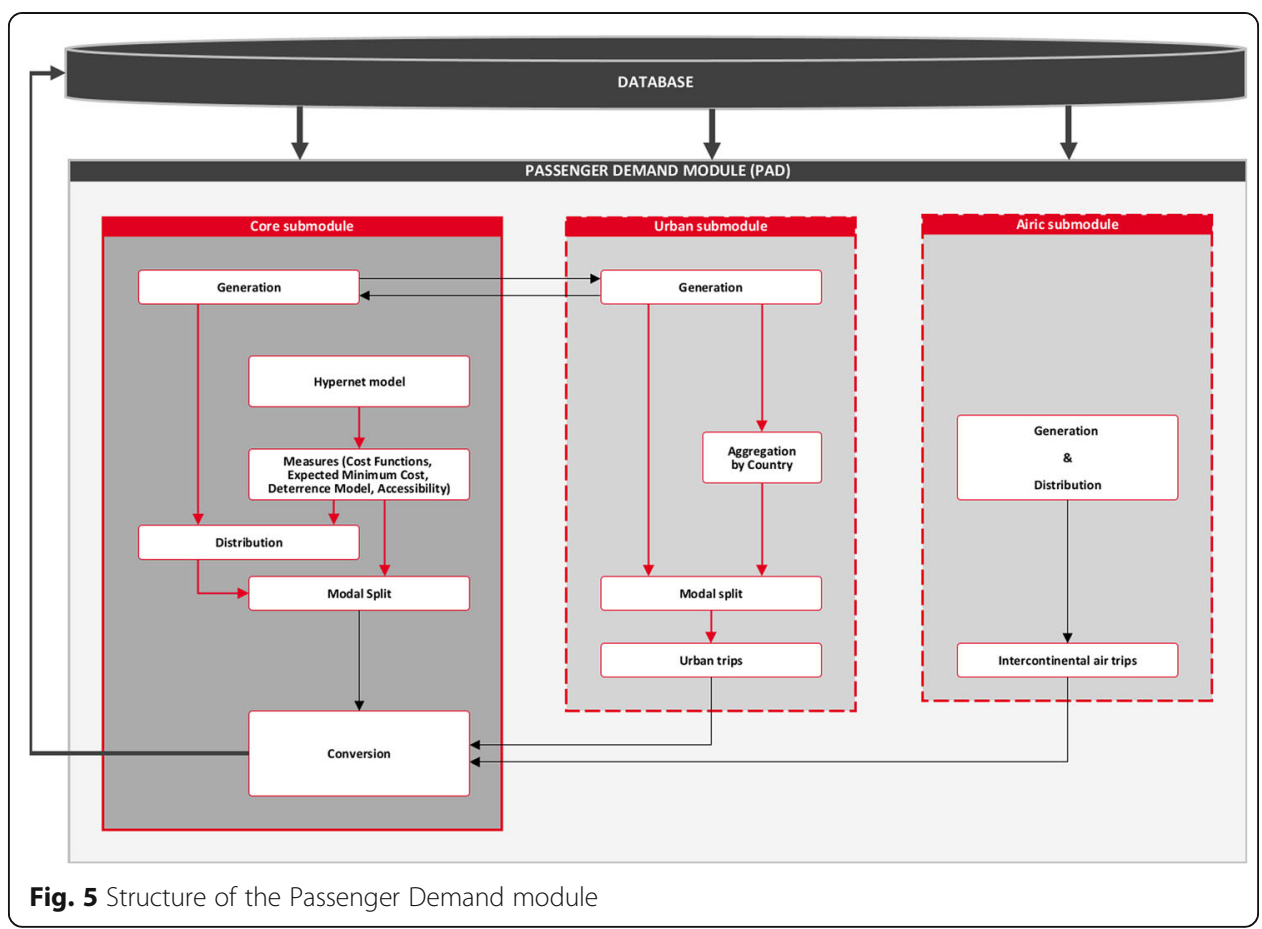

by country under consideration of four trip purposes and eight age groups. They are computed by a regression approach that takes economic and demographic changes in European countries into account with the regression approach being calibrated for the first year 2010 based on ETISplus data (Szimba et al. 2013). For the forecast years and for the policy scenarios trip rate factors are dependent on changes of the explanatory variables GDP, employment, and income level. PAD is therefore sensitive to economic and demographic changes.

In an intermediate step, four indicators are subsequently computed in order to integrate the trip distribution and the modal split model. First, Generalized Travel Times $\left(G T T_{i j m}\right)$ are computed by the cost functions based on travel impedance indicators, such as travel time, travel distance and level of service. All inter-zonal public transport modes (rail, air, coach) are considered by the GTT calculation as trip chains consisting of access mode, main mode and egress mode. GTTs follow the concept of travel time in which the cost unit refers to minutes rather than to monetary terms. Second, based on GTTs, Expected Minimum Costs $\left(E M C_{i j}\right)$ and market shares of transport modes $\left(S_{i j m}\right)$ are computed by a Nested Logit model following the concept of logsums (De Jong et al. 2007). Third, Deterrence Values $\left(D V_{i j}\right)$ are calculated by the deterrence model and in the last step, Accessibilities $\left(A_{i j}\right)$ are computed based on EMCs and DVs. Finally, $A_{i j}$ are used by the trip distribution model for the computation of the O/D trip matrix, and $S_{i j m}$ by the modal split model in order to divide the matrix by transport mode.

The last modelling step is the conversion stage. In this step, transport performance indicators (passenger-kilometers and vehicle-kilometers) are derived, based on the O/D trip matrices, as well as travel distances and occupancy rates from ETISplus. In addition, road trips are split by car and powered two-wheelers, under the assumption of country-specific shares and motorization levels. 
The core PAD module is complemented by two additional modules, the urban passenger demand, and the intercontinental air passenger sub-module.

The urban passenger demand sub-module computes the number of urban trips per year at country level. It distinguishes six transport modes: Car, motorcycle, tram/ metro, bus, cycling, walking. Given that urban trips by car and motorcycle are a subset of the intra-zonal NUTS-2 trip demand modelled by the core PAD module, the urban sub-module is linked to the generation step of the core PAD module in order to ensure the overall consistency.

The urban sub-module follows a generic, elasticity-based approach and consists of a generation, a modal split, and a conversion model. In the first step, the number of urban trips is generated for each NUTS-2 region based on "urban share factors" and trip rate factors. The "urban share factors" contain the share of the urban population which are pre-calculated for each NUTS-2 region on the basis of GIS data. Also the trip rate factors are pre-calculated for each NUTS-2 region. They rely on trip purpose-specific trip rates derived from household surveys. In the second step, the market shares for each urban transport mode is estimated under application of a logit model for the three transport mode categories: private road, public transport and slow modes. Finally, the conversion model disaggregates the three mode categories into the six transport modes and computes aggregated demand indicators at country level.

The intercontinental air passenger sub-module uses a regression-based approach to estimate the number of flights respectively demand between European regions and intercontinental destinations based on socio-economic data, regional attractors and network impedances. In general air transportation impedances consider cost structures such as $\mathrm{CO}_{2}$ taxation, national air transport charges or expenditures calculated by airlines in respect of passenger rights. The split between European and intercontinental air transport mirrors the necessity to deal with the different regional granulation underlying the assessment model's purpose: while Europe is in the focus and modeled at regional level (NUTS-2), the other regions of the world are considered through a less detailed approach, i.e. 19 aggregated zones such as Far East, USA, Russia, or South-America. In order to avoid biased model results because of a highly different size of assumed traffic cells, air demand modeling has been split.

The PAD module's most important input data are population and labor force data at regional level by DEM, regional GDP, GVA and employment by ECR, as well as the vehicle stock and generalized fixed and variable costs per vehicle-km (differentiated by country, mode and fuel type) by VES.

The module's main outputs to other modules are transport demand (vehicle mileage, passenger-kilometers, number of passengers) by mode and region, as well as costs by region and origin/destination relation to ECR, transport demand and vehicle occupancy rates to VES, transport demand (vehicle mileage by O/D, origin and mode, and differentiated by urban and non-urban) to ENV and SAF.

Figure 5 displays the structural overview of the Passenger Demand module.

\section{Freight demand module}

The Freight Demand (FRD) module uses national and international freight transport chains as a base. FRD consists of four components: trade conversion, distribution, 
mode split and conversion (see Fig. 6). Together with the Economy \& Resources module, it follows an approach analogue to the classical four-step methodology of generation, distribution, modal split and assignment. The latter is replaced by calculation of performance indicators in the conversion component.

The module delivers trade in value by production-consumption location $(\mathrm{P} / \mathrm{C})$, which is converted to volumes, applying volume density assumptions per $\mathrm{O} / \mathrm{D}$ (related to legs in a chain between production and consumption location) and commodity (assumed constant over time) extracted from ETISplus (Szimba et al. 2013).

The trade projections are produced by the Economy \& Resources module (in Euro, 2010 constant values). The input from the Economy \& Resources module is defined by sectors that (apart from transport sectors) match commodity types $c$. The trade projections are used to calculate growth factors. As such the freight model can be regarded as a marginal model. The FRD applies the value/volume conversion method from NEAC-10 to ETISplus data to estimate the volumes in tons per year $\left(T_{t, i j, j}\right)$ by commodity type $c$ and production-consumption relation $i j$ as follows:

$$
T_{t, i . j . c}=a_{c i \ni i, c j \ni j, c} * b_{c i \ni, c j \ni j, c} * c_{c i \ni i, c j \ni j, c} * V_{t, i, j, c}
$$

where:

$T_{i t, i, j, c}$ Freight trade flow of commodity $c$ between production and consumption location $i$ and $j$ in time period $t$ [tonnes]

$a_{c i, c j, c}$ Value-volume ratio for trade from production country $c i$ to consumption country $c j$ per commodity type $c$ [Euro]

$b_{c i, c j, c}$ Logistics factor for domestic trade when country $c i$ is country $c j$

$c_{c i, c j, c}$ Logistics factor for intra-zonal trade when zone $i$ is zone $j$.

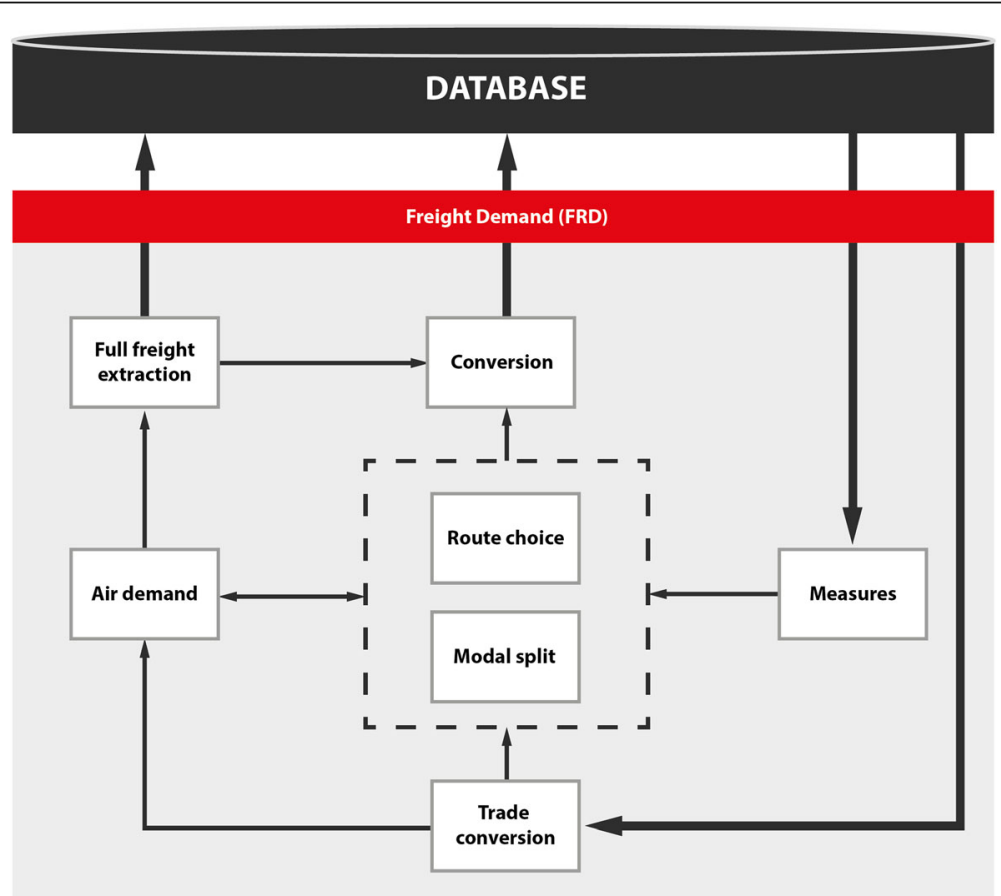

Fig. 6 Structure of the Freight Demand module 
Kiel et al. (2016a, 2016b) and Van Grol et al. (2016a) contain a more detailed methodology description of the freight demand model and the calibrated values of the model parameters.

The distribution of mode chains follows a multinomial logit model and distributes the freight flow across multi-modal transport chains (routed through transshipment points) collected from the ETISplus database. In HIGH-TOOL a mode chain constitutes a multimodal routing from production location to consumption location through up to two transshipment points. The ETISplus database provides multimodal freight flows (in tons) per production-consumption location pair $i j$ in the form of mode chains $r$ using at most two transshipment points. The probability $\left(P_{t, I, j, c, r}\right)$ of using a specific route $r$ is calculated as follows:

$$
P_{t, i, j, c, c, r}=\frac{e^{T C_{t, i, j, c, r}}}{\sum_{m \in M} e^{T C_{t, i, j, c, r}}}
$$

in which

$$
T C_{t, i, j, c, r}=\beta^{0} \text { min_cost }_{t, i, j, c, r}
$$

where:

$\mathrm{P}_{\mathrm{t}, \mathrm{i}, \mathrm{j}, \mathrm{r}, \mathrm{r} \mid \mathrm{m}}$ Probability of choosing route $\mathrm{r}$ between consumption location $i$ and production location $j$ for commodity $c$ in time period $t$ give mode $m$ [\%]

$T C_{t, I, j, c, r}$ Minimal total costs for route $r$ between production location $i$ and consumption location $j$ for commodity $c$ at time period $t$

$\min _{-}$costt,i,j,r,c Minimum total cost of route $\mathrm{r}$ between consumption location $i$ and production location $j$ for commodity $c$ in time period $t$

\section{$\beta^{0}$ Constant}

$r$ The route for a production-consumption location pair given the set of mode(s) $m$ used to traverse it.

The specific set of modes used in a route allows it to be differentiated from another route going through the same transshipment points. The modal combination with lowest costs for a certain route is used as a proxy for the attractiveness of all routes connecting the production-consumption location pair $i j$.

Here, the probability that a specific route is selected for a $\mathrm{P} / \mathrm{C}$ pair $i j$ is calculated by comparing the estimated costs for all available routes. The number of total tons as provided in the previous step is applied on these routes to obtain route flows $\left(T_{t, i j, c, r}\right)$ :

$$
T_{t, i, j, c, r}=T_{t, i, j, c,} * P_{t, i, j, c, r}
$$

where:

$T_{t, i j, c, r}$ Freight flow for commodity $c$ from production location $i$ to consumption location $j$ in time period $t$ using route $r$ [tons]

$P_{t, i j, c, r}$ Probability choosing route $r$ between production location $i$ to consumption location $j$ for commodity $c$ in time period $t$ [\%]

$T_{t, i j, c}$ Freight flow for commodity $c$ from production location $i$ to consumption location $j$ in time period $t$ [tons].

The end product of this step is for each $\mathrm{P} / \mathrm{C}$ pair $i j$ a list of chains with allocated tons. Van Grol et al. (2016) provides a detailed description of the distribution of chains. The 
mode split calculation is based on the approach applied in ETISplus and the NEAC-10 model (Newton et al. 2015). The cost functions and utilities in the modal split component rely on TRANSTOOLS v2. The modal split calculation estimates a modal share for each leg of the chains produced by the distribution step. For each of these legs the total leg costs are the summation of the costs encountered in each country traversed along the leg.

Each origin and destination is connected by the transport routes extracted from the ETISplus database. These transport routes are part of transport chains that form a set of up to three legs that connect an origin and destination through up to two transshipment regions. For each of the legs the modal split calculation is applied. The modal split component considers various cost elements such as fixed costs, variable costs, energy costs, waiting costs, and loading/unloading costs. These are influenced by the VES module that can be affected by policy measures to compute generalized cost per available mode connecting an origin and destination of a leg through a multinomial logit function according to TRANSTOOLS (Burgess et al. 2008; NEA 2007). Van Grol et al. (2016) provides a detailed description of the mode split model.

The mode split model uses the following logit approach:

$$
P_{m \mid c d i j}=\frac{e^{V_{m \mid c i j}}}{\sum_{m \in M} e^{V_{m \mid c i j}}}
$$

with

$$
V_{m \mid c i j}=\alpha_{c m} c_{m c i j}+\beta_{c m}
$$

where:

$\mathrm{P}_{\mathrm{m} \mid \mathrm{cij}}$ Probability of choosing mode $\mathrm{m}$ given commodity group $c$, origin $i$ and destination $j$

$V_{m \mid c i j}$ Utility of mode $m$ for commodity group $c$ and O/D relation $i j$

$C_{m c i j}$ Costs for mode $m$ given commodity group $c$ and O/D relation $i j$

$\alpha_{c m}$ Logit parameter for commodity group c and mode $\mathrm{m}$

$\beta_{c m}$ Constant for commodity $c$ and mode $m$

$m$ Set of available modes (road, rail, inland shipping, sea, other).

Subsequently based on total generalized costs for routes connecting the trade relation's origin and destination, demand is distributed across the route's chains connecting origin and destination through transshipment regions in the route choice component. As the model uses a hyper network connecting the different zones, the route choice is performed at an aggregated level. The changes in route choice are expressed as changes in time and/or distance which are translated into fixed, variable and energy costs.

The translation of the chain matrices into unimodal demand matrices is fairly straight forward. Each chain comprises up to a maximum of three legs. Each leg contains an origin and destination. The origin or destination can be the production or consumption location, but they can also be the transshipment points. The chain matrix is split into different leg-matrices by commodity group and mode. This results in mode specific matrices by commodity group that can be used to calculate the ton-kilometers by mode and commodity. 
The translation of the unimodal demand matrices in tons into trip matrices is done by using assumptions on the development of the average load per mode or vehicle and the share of empty trips. This has been calibrated for the base year, in order to achieve consistency with the amount of trips reported by statistics.

The conversion step, i.e. the calculation of transport demand performance indicators (ton-kilometer and vehicle-kilometer), is conducted both for the origin region and related to the "on the territory" perspective. The latter is calculated by applying the shares of distances of a leg per country, using data from ETISplus.

Finally, assumptions on share of only-cargo flights and capacity of air freight transport are applied to extract air freight transport by only-cargo aircraft from the total demand for air transport.

The module's most important input data are regional trade data (differentiated by commodities) from ECR, and generalized fixed and variable costs per vehicle-km (differentiated by country, mode and fuel type) from VES.

The module's main outputs to other modules are transport demand by mode and commodity (vehicle mileage, ton-kilometers, tons carried) as well as transport costs by region and origin/destination relation to ECR, transport demand and vehicle occupancy rates to VES, transport demand (vehicle mileage by $\mathrm{O} / \mathrm{D}$, mode and commodity) to ENV and vehicle mileage by country and mode on the basis of the "on the territory" principle to SAF.

\section{Environment module}

The Environment (ENV) module calculates wheel-to-tank fuel consumption and emissions for each vehicle type. The key variables in this calculation are fuel consumption or fuel intensity, and emission factors or emission index. These factors are divided into technologies that are represented in the module by age cohort or vintage.

The module produces estimates of $\mathrm{CO}_{2}$ emissions and five other pollutants: $\mathrm{CO}$, VOC, $\mathrm{NOx}, \mathrm{SO}_{2}$ and PM2.5. Fuel consumption and emissions are calculated per origin country and disaggregated to zones based on the share of transport demand in each zone.

The module comprises of two parts (see Fig. 7). Firstly, the predicted transport demand segmented by country, mode and fuel type is disaggregated by vehicle type and vehicle technology (represented by the vehicle age cohort). Secondly, fuel consumption and emissions are derived and calculated for each mode, vehicle type, fuel, and age cohort (technology) using the previously disaggregated transport demand, fuel consumption and emission factors.

Data on fuel consumption and emission factors for all vehicle age cohorts (technology) are available for the year 2010. For each period in the remaining simulation period (2015-2050), only factors of the new vehicles (vehicles between 0 and 4 years old) are available in the dataset. These factors are modifiable to enable policy simulation, such as introduction of new emission standards in a specific time or simulation period.

Fuel consumption and emission factors of older vehicles (vehicles more than 4 years old) are derived from the dataset for the previous period.

The ENV module uses vehicle mileage data (differentiated by O/D and mode) from PAD and FRD. The vehicle mileage used by PAD differentiates between urban and 


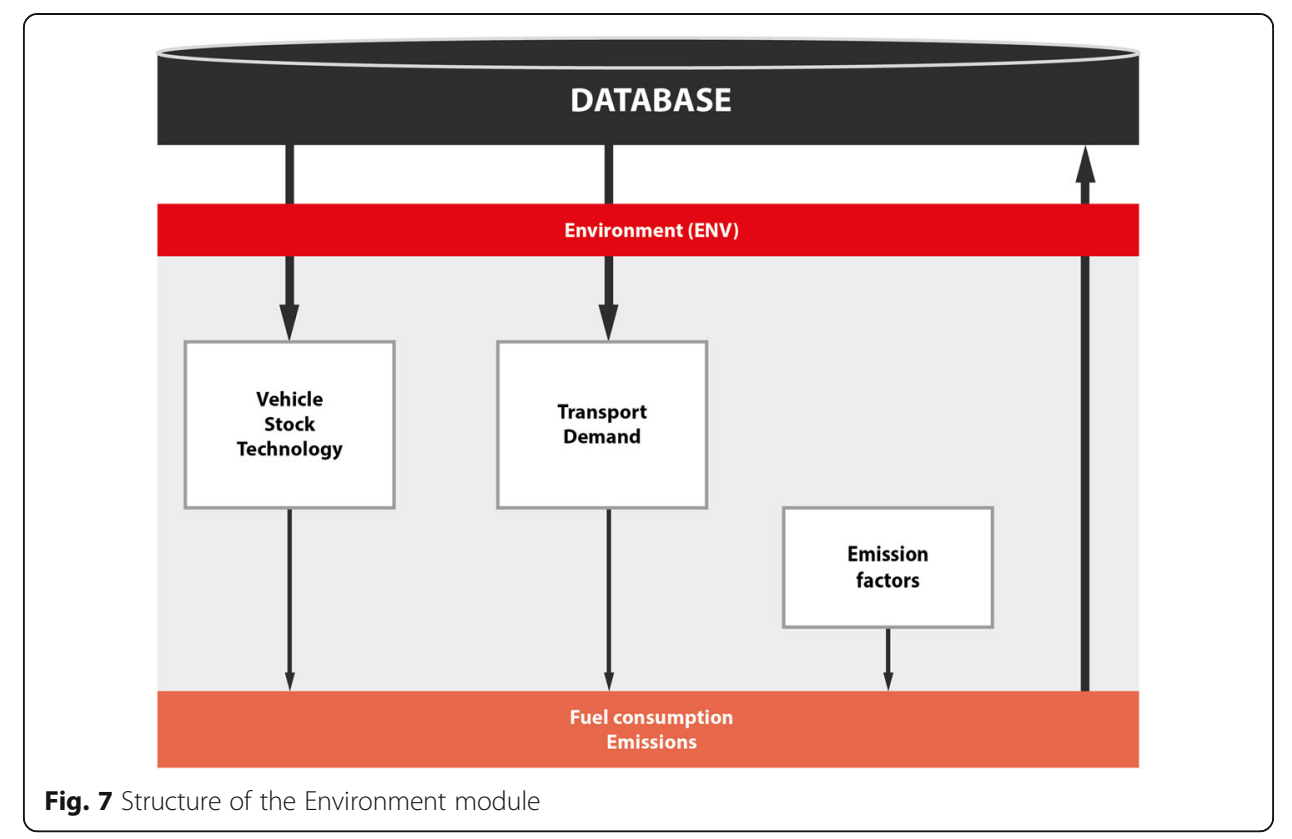

non-urban transport, while the FRD data differentiate by commodity. Furthermore, VES provides the vehicle fleet by country, mode, fuel type, vehicle type and vehicle technology. There are no data flows from ENV to any other core module.

\section{Safety module}

The Safety module (SAF) assesses the impact of transport policy measures on safety, and yields predictions of the number of fatalities and injuries, and associated social costs (see Fig. 8).

The required input includes historical mobility data from the Data Stock, predicted mobility (from the Passenger and Freight Demand modules), and user input changes to safety risk and safety risk causal factors. Risk is defined as the number of occurrences (fatalities, injuries) per unit of mobility (in vehicle-kilometer or number of trips).

The module distinguishes between road and non-road modes, that are subsequently dealt with at different levels of detail. Road safety is treated in the most detail and predicts fatalities as well as serious and minor injuries. Road is further split into car, truck, powered two-wheelers, public transport, bike, and pedestrians. Non-road modes include rail, air, short sea shipping, and inland waterways.

The results are computed per country and time period.

For each transport mode, there are two components. The first is the Business-as-Usual (BAU), which calculates safety risks and makes predictions based on risk trend lines (from historical mobility and safety data) and mobility predictions (from the Passenger and Freight Demand modules). The second is the scenario component that adapts the BAU risks according to the anticipated effect of safety measures modelled. The effect is derived from changes in accident causal factors (which are the policy inputs) and the elasticities and equations relating these to changes in risk. Safety predictions for the scenario follow from these scenario risks and mobility predictions. Road fatalities, serious and minor injuries are predicted. For the other transport modes, 


\section{DATABASE}

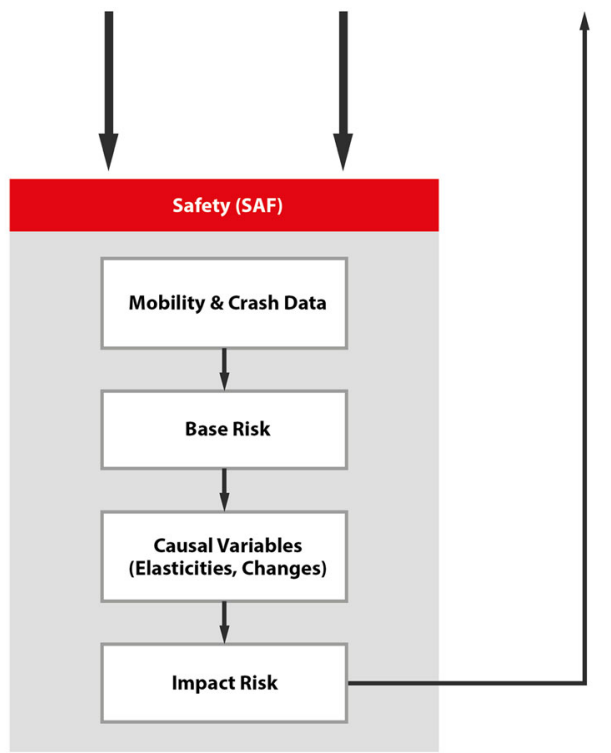

Fig. 8 Structure of the Safety module

the focus is on fatalities. For all modes the social costs are calculated. The general approach of adjusting risk trends based on changes in accident causal factors is based on the European Road Safety Action Program (ERSAP) (Delhaye et al. 2010).

The SAF module uses vehicle mileage by country and mode on the basis of the "on the territory" principle from PAD and FRD. Furthermore, passenger demand data (passenger-kilometers, number of trips) per country, age group and gender, differentiated by urban and non-urban transport, are used from PAD. The module does not provide any data to other core modules.

\section{Module interaction}

The core modules interact sequentially with each other. The sequential solution reduces the computation loops, as results for a period $t$ are passed to computations in $t+1$. An iterative process would be much more time consuming as the modules would interact, re-compute, store and read data several times until the results for a certain time period become available and the model can move forward to the next time period. The sequence starts with DEM to produce demographic outputs for all forecast years 2015-2050. Subsequently ECR is run, fed by DEM results of time step $t$ and by VES, PAD and FRD outputs of time step $t-1$. Afterwards VES is activated, on the basis of DEM/ECR (step $t$ ), and PAD/FRD (step t-1) outputs. Subsequently, PAD and FRD are run, using results from DEM/ECR/VES, and ECR/VES, respectively. Finally, results by PAD, FRD and VES are delivered for all years to ENV for the computation of the environmental impacts and by PAD and FRD to SAF for the computation of the safety impacts. The tool's base year is 2010. Thus, the first time step 2015 is partly driven by 2010 results, and 2020 by 2015 results etc.

The interaction scheme is shown by Fig. 9. 

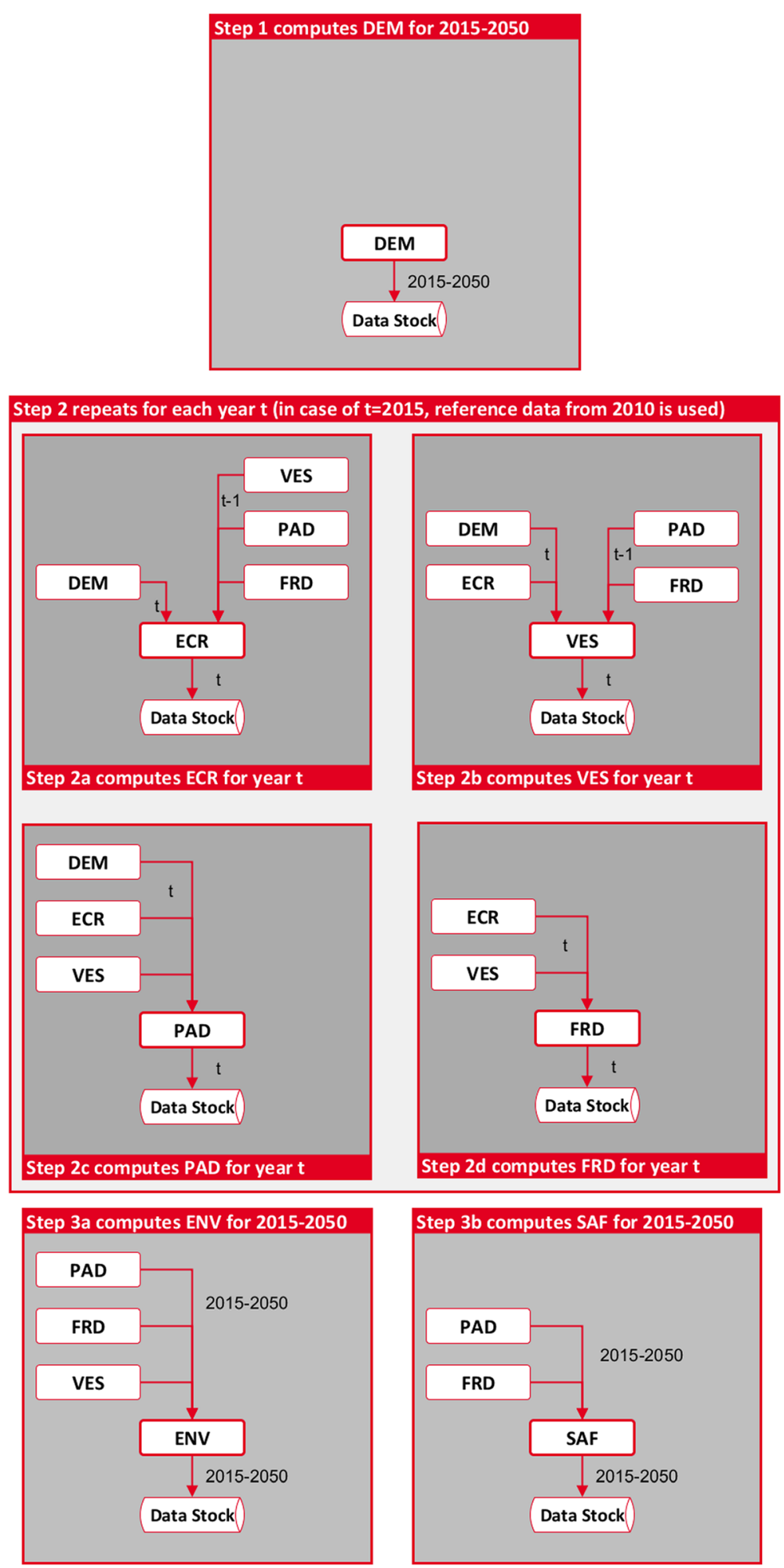

Fig. 9 Model execution order 


\section{Model validation}

The HIGH-TOOL model was subjected to an extensive validation and testing approach, consisting of: robustness tests to ensure that the model is capable of discovering invalid inputs; check of coherence of model outputs with the EU Reference Scenario 2013 (European Commission 2013); comparison of model outputs with the ASTRA-EC model; sensitivity tests to test the plausibility of the modules' reactions on changes in input variables; and the conduction of case studies (see van Meijeren et al., 2016; Kiel et al. (2016a)).

Since the results of the HIGH-TOOL baseline required consistency with the forecasts of the EU Reference Scenario 2013 (EU Ref), significant effort was spent to validate the HIGH-TOOL modules against this reference. The validation approach embraced both the validation of each module as stand-alone module and the validation of the integrated tool, in which all modules are interconnected with each other.

As an example of validation outcomes, Table 1 compares the modelled rail passenger transport demand for the years 2010, 2020, 2030 and 2050 with the forecasts by the EU Reference Scenario 2013, while Table 2 shows the development of the total freight transport demand.

Overall the validation analyses have revealed a high level of consistency between HIGH-TOOL results and the EU Reference Scenario 2013. Any major differences, which occur for a limited number of results, can be well explained, largely by differences in data definition. Moreover, the differences between forecasts by HIGH-TOOL and the EU Reference Scenario are explained by the pattern that no information was accessible concerning how the policy measures underlying the EU Reference Scenario 2013 have been operationalized into the PRIMES model for the generation of the forecasts. Thus also differences how the policies underlying the EU Reference Scenario 2013 have been operationalized by HIGH-TOOL and PRIMES, explain differences among the results. More details on validation approach and results are provided by van Meijeren et al. (2016).

\section{Transport policy measures}

\section{Operationalization}

Transport Policy Measures (TPMs) are implemented in HIGH-TOOL by a specific set of policy levers (or input parameters of the HIGH-TOOL model) and associated values. To arrive at the set and the values for the policy levers several sources have been reviewed. These sources differ in the strength of their underpinning and the scalability of parameter values to the spatial level that is considered in HIGH-TOOL. The following sources have been reviewed (see Van Grol et al., 2016):

Table 1 HIGH-TOOL results vs. EU Ref, rail passenger transport demand (million pkm)

\begin{tabular}{lllllll}
\hline & 2010 & 2010 & 2030 & 2030 & 2050 & 2050 \\
& HIGH-TOOL & EU Ref & HIGH-TOOL & EU Ref & HIGH-TOOL & EU Ref \\
\hline EU28 & 417,213 & 405,505 & 581,036 & 606,485 & 708,525 & 770,552 \\
EU15 & 371,151 & 359,537 & 499,760 & 520,224 & 602,662 & 656,002 \\
EU13 & 46,063 & 45,967 & 81,276 & 86,260 & 105,863 & 114,551 \\
\hline
\end{tabular}


Table 2 HIGH-TOOL results vs. EU Ref, EU28 + 2 total freight transport demand (million tkm)

\begin{tabular}{|c|c|c|c|c|c|c|}
\hline & $\begin{array}{l}2010 \\
\text { HIGH-TOOL }\end{array}$ & $\begin{array}{l}2010 \\
\text { EU Ref }\end{array}$ & $\begin{array}{l}2030 \\
\text { HIGH-TOOL }\end{array}$ & $\begin{array}{l}2030 \\
\text { EU Ref }\end{array}$ & $\begin{array}{l}2050 \\
\text { HIGH-TOOL }\end{array}$ & $\begin{array}{l}2050 \\
\text { EU Ref }\end{array}$ \\
\hline EU28 & $2,239,665$ & $2,312,415$ & $3,175,986$ & $3,199,693$ & $4,102,472$ & $3,652,618$ \\
\hline EU15 & $1,663,948$ & $1,718,291$ & $2,279,797$ & $2,305,708$ & $2,871,405$ & $2,616,397$ \\
\hline EU13 & 575,717 & 594,124 & 896,189 & 898,386 & $1,231,067$ & $1,042,883$ \\
\hline
\end{tabular}

(1) Large-scale (European) model applications - TPMs that have been modelled in models such as SUMMA, EXPEDITE, and TRANSTOOLS.

(2) Examples from practice - TPMs that have already been implemented in practice and are described in the literature.

(3) Research publications - TPMs for which useful information was found in research publications. Most of these studies describe model simulations, field tests, surveys, or expert judgement.

(4) Qualitative guidelines - TPMs for which a qualitative description of policy impacts is adapted from the ASSIST project.

Under consideration of this review, one or more variables of the HIGH-TOOL model have been selected for each TPM, which translate a TPM's effect on the transport sector. For a majority of the TPMs, mode-specific user cost variables, i.e. elements of the generalized cost functions, have been selected to operationalize a TPM.

Detailed information on how the different policy measures are operationalized is provided by Mandel et al. (2016). In this project report each transport policy measure is categorized, and its general impact mechanism is drafted. Furthermore, the report provides a documentation on which specific model variable(s) is (are) altered in order to operationalize a transport policy measure.

\section{Policy selection}

Instead of embracing a dedicated transport supply module, the HIGH-TOOL instrument's supply parameters can be adjusted by the user either indirectly by the selection of transport policy measures or bundles, or directly by changing specific policy levers. Furthermore, the experienced user may conduct any change in the tool's database to simulate specific policies.

The HIGH-TOOL instrument offers 30 pre-defined Transport Policy Measures (TPM), which can be selected either individually or in combinations. The scope of the pre-defined Transport Policy Measures is shown by Table 3.

Policies can be specified by the user in terms of intensity, temporal effectiveness (2015 to 2050) and geographical distribution (countries and regions in Europe).

Also combinations of pre-defined TPMs can be applied. All combinations of TPMs have been analyzed in terms of interdependencies (see section "Consideration of policy bundles"). While the majority of the policies have been revealed to be additive, the user is informed by the system on the existence of interdependencies, if interdependent policy combinations are chosen.

Furthermore, customized policy packages can be defined using any combination of policy levers. The policy levers are organized per module. The number of levers per module are shown in Table 4. 
Table 3 Transport Policy Measures covered by HIGH-TOOL

\begin{tabular}{|c|c|}
\hline Category & Single Pre-Defined Transport Policy Measures \\
\hline \multirow[t]{8}{*}{ Efficiency standards and flanking measures } & Improving local public transport \\
\hline & Deployment of efficient vehicles \\
\hline & Replacement of inefficient LDVs and buses \\
\hline & HDV limitation for urban areas \\
\hline & LDV speed limit \\
\hline & Diffusion of $\mathrm{H}_{2}$ fuel cell cars \\
\hline & Diffusion of electro cars \\
\hline & Replacement of inefficient cars \\
\hline \multirow[t]{6}{*}{ Pricing } & $\mathrm{CO}_{2}$ feebates for road transport \\
\hline & $\mathrm{CO}_{2}$ certificate system for road transport \\
\hline & Circulation tax for cars \\
\hline & Internalization of external costs \\
\hline & HDV infrastructure change \\
\hline & Urban road charging \\
\hline \multirow[t]{5}{*}{ Research and innovation } & Intelligent road vehicles \\
\hline & Dynamic traffic management for road \\
\hline & Intelligent traffic information system for road \\
\hline & Road vehicle safety technology protecting other transport users \\
\hline & Safety systems for road vehicle users \\
\hline \multirow[t]{11}{*}{ Internal market } & Acceleration of TEN-T implementation \\
\hline & River information system \\
\hline & European Rail Traffic Management System \\
\hline & Harmonized handling of dangerous goods \\
\hline & Harmonization of rail safety \\
\hline & Harmonized social rules for truck drivers \\
\hline & Opening the internal IWW market \\
\hline & Enhance service quality at ports \\
\hline & Maritime traffic management system \\
\hline & Freight corridor management \\
\hline & Single rail vehicle authorization and certification \\
\hline
\end{tabular}

Finally, using the Expert Mode the user can edit input tables and/or the hypernet to control the impedances used in the model. The Expert Mode is an optional feature for advanced editing of the database values before running the model.

\section{Consideration of policy bundles}

When TPMs are combined their dependency is analyzed by reviewing a possible overlap in policy levers. If the sets of policy levers do not overlap, the TPMs are independent and their result additive. If the sets of policy levers do overlap, special care is needed in the implementation of policy lever values because these TPMs may not be completely independent. Depending on the nature of the involved TPMs, the combined effect of their policy levers might be as follows: 
Table 4 Number of policy levers per module for the Customised Policy package interface

\begin{tabular}{ll}
\hline Module & Number of individual levers \\
\hline Economy and Resources & 3 \\
Vehicle Stock & 430 \\
Passenger Demand & 100 \\
Freight Demand & 79 \\
Environment & 127 \\
Safety & 60 \\
\hline
\end{tabular}

(1) Reduced - when TPMs are conflicting and cancel each other out;

(2) Maximized - the effect of the combined TPMs equals the effect of the strongest TPM;

(3) Limited - combining the TPM has some added effect, but this added effect is limited, and

(4) Maximum - although the TPMs share the same policy levers they are independent and thus additive.

There are no pairs of TPMs that fall into the first group, while pairs in the last group can be freely combined by adding up their policy lever values. However, six groups of TPMs have been identified that share the same policy levers and are considered to be partly or largely overlapping. For the shared policy levers of these groups it has been defined how to model them simultaneously (see Van Grol et al., 2016).

\section{The hypernet approach}

With its requirement to provide assessment results quickly and at a strategic level, the HIGH-TOOL model is not a network-based transport model such as TRANSTOOLS. Nevertheless, the passenger and freight demand modules are based on transportation impedances at the level of NUTS-2 O/D relations. The impedances for the HIGH-TOOL base year 2010 are founded on ETISplus impedances, while the baseline's impedances for the forecast years have been computed by the network-based transport model Vaclav for the infrastructure configuration underlying the EU Reference Scenario, and aligned with the impedances for the year 2010.

This approach allows the modelling of infrastructure policies by modifying mode-specific travel impedances generically for transport in the whole EU, selected countries or selected NUTS-2 regions, which however does not allow the consideration of network effects of infrastructure policies.

Therefore, in order to allow the consideration of network effects in the strategic assessment of transport infrastructure policies, a "hypernet" approach was developed. The hypernet approach allows the change of travel impedances on a virtual link between two NUTS-2 regions. After running a shortest-path algorithm new impedance matrices are obtained, thus covering the network dimension of the infrastructure policy. The hypernet is an optional submodule covering road and rail and is linked to the passenger demand module.

For the creation of the hypernet, regions have been connected in the hypernet if: either the zones are bordering each other and have an ETISplus network link that 
connects both zones, or they are connected by a ferry link in the ETISplus network. A representative NUTS-3 zone, i.e. the NUTS-3 zone containing the largest city/ capital city within the NUTS-2 zone, was chosen for each NUTS-2 zone. Each hypernet node is allocated an access/ egress impedance to model travel impedances to access the inter-regional hypernet links. The intra-zonal impedances are based on inter-NUTS-3 impedance values from ETISplus and can be influenced by policies. Also the inter-zonal impedances are based on the ETISplus impedance matrices. Future travel impedances up to the model's forecast horizon 2050 were calculated from enhanced ETISplus networks, including all infrastructure projects planned on the TEN-T core and comprehensive networks (see European Union, 2013).

Figure 10 displays the constructed hyper-network links for road (ETISplus road network (red), Zone centroids (green) and constructed HIGH-TOOL road hypernet (blue) for the base year 2010).

\section{Case study}

\section{Case study description}

This case study examines the application of the hypernet facility of the HIGH-TOOL instrument. The assumption is made that rail passenger travel times will further decrease by $10 \%$ along the "Magistrale" corridor Paris-Strasbourg-Karlsruhe-MunichVienna-Bratislava (see Fig. 11). The travel time decrease is assumed to be on top of the time savings due to TEN-T/CEF policies already in the baseline scenario. Thus, the investment assumptions do not refer to concrete rail infrastructure projects, but are hypothetical. The infrastructure improvements are assumed to become effective in the year 2030. Further details on this case study are provided by Kiel et al. (2016b).

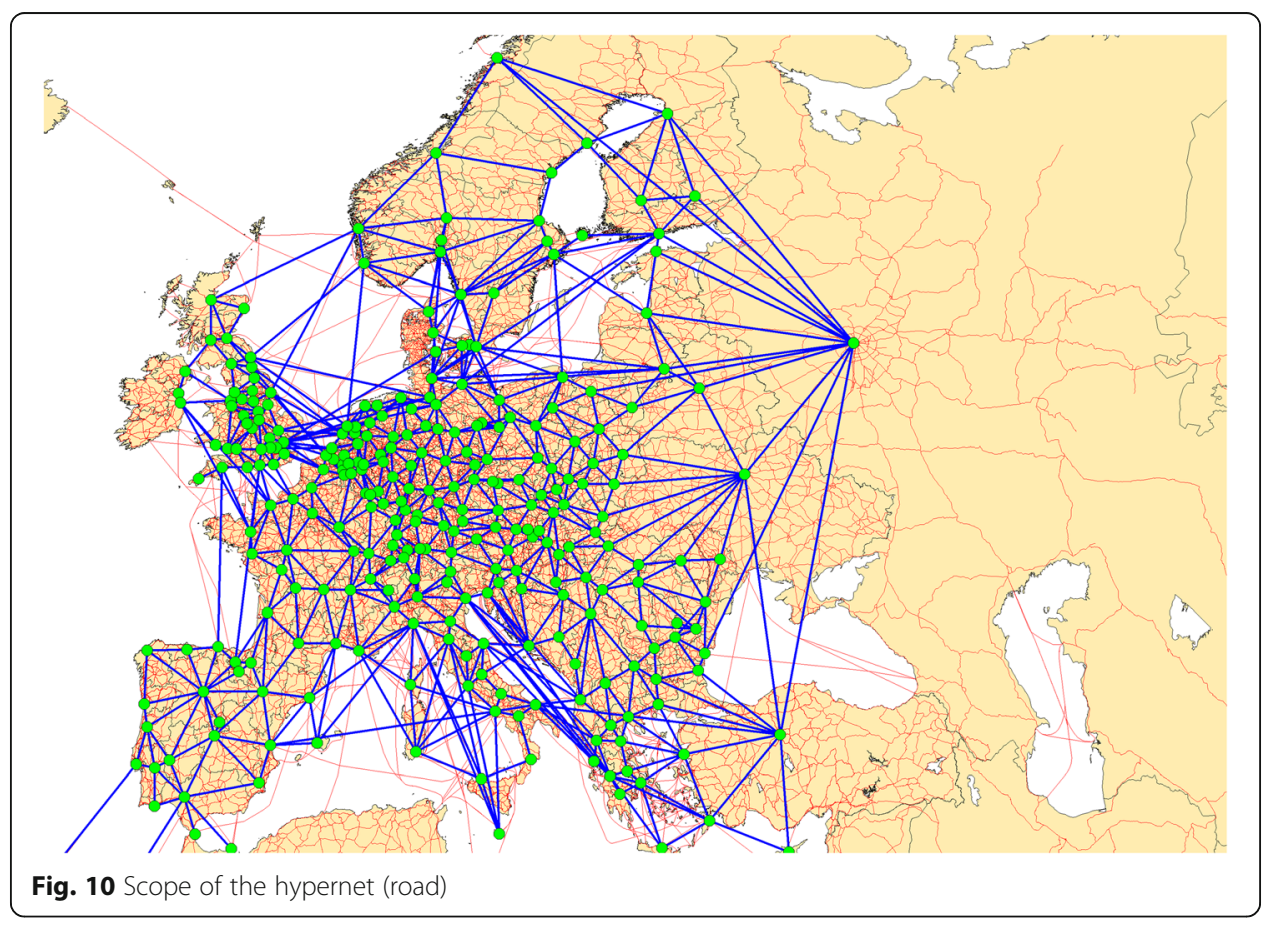




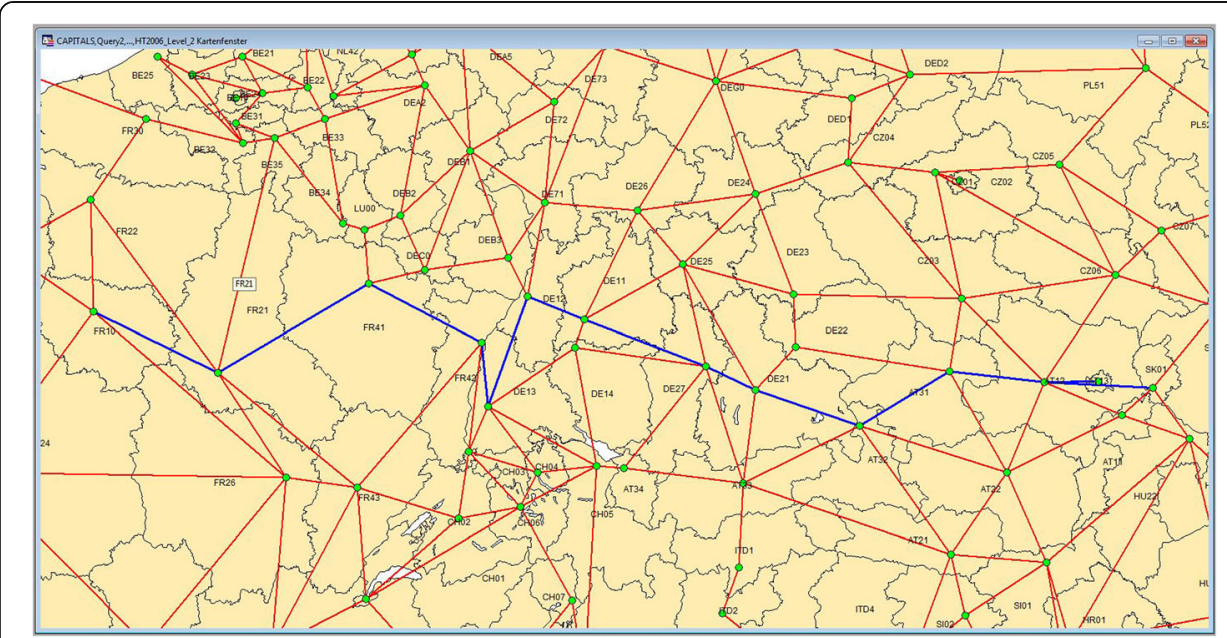

Fig. 11 Map showing the hypernet rail links of the Magistrale corridor (blue), other hypernet rail links (red) and NUTS-2 zone centroids (green)

\section{Model results}

The model predicts an increase in rail passenger demand while the demand of Acknowledgements modes (road - i.e. private passenger cars -, coach and air) is expected to decrease (see Table 5). The results do not only reveal a mode shift effect, but also reveal that the increase in rail passenger-kilometers exceeds the loss of passenger-kilometers by competing mode. Thus, the assumed improvement of rail level-of-service is expected to generate induced traffic that explains almost half of the additional rail traffic demand. This pattern is largely in line with the observations made for the French high-speed rail line Paris-Lyon (Vickerman 1996) and can be explained by direct and indirect effects, such as changes in travelers' mobility behavior and the emerging of new activities due to the reduced travel time (Cascetta and Coppola 2013).

The percentage changes in relation to the total passenger transport demand are relatively limited, which is explained by the limited geographical scope of the measures, as well as by the pattern that the assumed infrastructure improvements relate to inter-zonal passenger transport flows at the level of NUTS-2, which represent only a small share of the overall market. In 2050, the rail passenger demand is expected to increase by $0.02 \%$ for EU28 + 2, representing 4.4 million passenger-kilometers per day (1.6 Gpkm per year). The results of our rather hypothetical case study are largely in line with the findings of the "Magistrale corridor study" predicting an increase of about 14 million rail passenger trips per year due to upgrading this railway corridor (IWW et al. 2001).

Regarding impacts on demand by mode of transport for 2050 at country level, the strongest impacts in absolute terms are expected for Germany, followed by France,

Table 5 Case study - Total passenger-kilometres 2010-2050, by modes (in million), EU28 + 2, difference Scenario-Baseline

\begin{tabular}{llllll}
\hline & 2030 & 2035 & 2040 & 2045 & 2050 \\
\hline Air & -45 & -55 & -53 & -55 & -55 \\
Rail & 1306 & 1569 & 1534 & 1575 & 1608 \\
Coach & -35 & -42 & -43 & -45 & -47 \\
Road & -605 & -743 & -713 & -734 & -742 \\
\hline
\end{tabular}


Austria and Slovakia (see Fig. 12). These countries are the key beneficiaries of the assumed infrastructure investments. Due to the network effects, which are covered by the hypernet approach, also the demand structures of other countries, which are not directly concerned by the investments - such as the Czech Republic, Italy and Romania - reveal slight impacts in favor of rail.

The modal shift from road and air to rail leads to a decrease in fuel consumption, $\mathrm{CO}_{2}$ emissions and the emission of air pollutants (see Table 6). Furthermore, the modal shift results in a slight reduction in the number of road accidents (see Table 7). Finally, the HIGH-TOOL model predicts moderate economic impacts (see Table 8): the decrease in rail passenger travel times results in savings in generalized costs and, thus, improves regional accessibility, which has a positive impact on Gross Value Added through provision of better access to labor markets and lower costs of intermediate goods (second order effects). The economic impacts do not embrace any first order effects (direct or multiplier effects of the infrastructure investments), as the underlying investment amount has not been specified for the purposes of the case study.

\section{Conclusions}

The HIGH-TOOL model is an open source instrument, is both publicly and freely available and does not require any commercial software products to be run. These features clearly distinguish the HIGH-TOOL model from any other European transport demand model or policy assessment instrument. The model's openness ensures thorough transparency of computations, and allows the experienced user to modify calculation methodologies, data or model parameters.

To develop the HIGH-TOOL model, originally independently functioning models have been integrated on a common platform. A key enabler of the development work in HIGH-TOOL was the European reference database ETISplus, covering a large share of data sets relevant for the models which were integrated in HIGH-TOOL. In this respect, HIGH-TOOL can be regarded as a logical consequence of the European Union's strategy to provide not only publicly available data for transport policy and modelling as accomplished by EU-funded projects such as ETIS-BASE and ETISplus -, but also to establish a publicly available open source tool for strategic policy assessment.

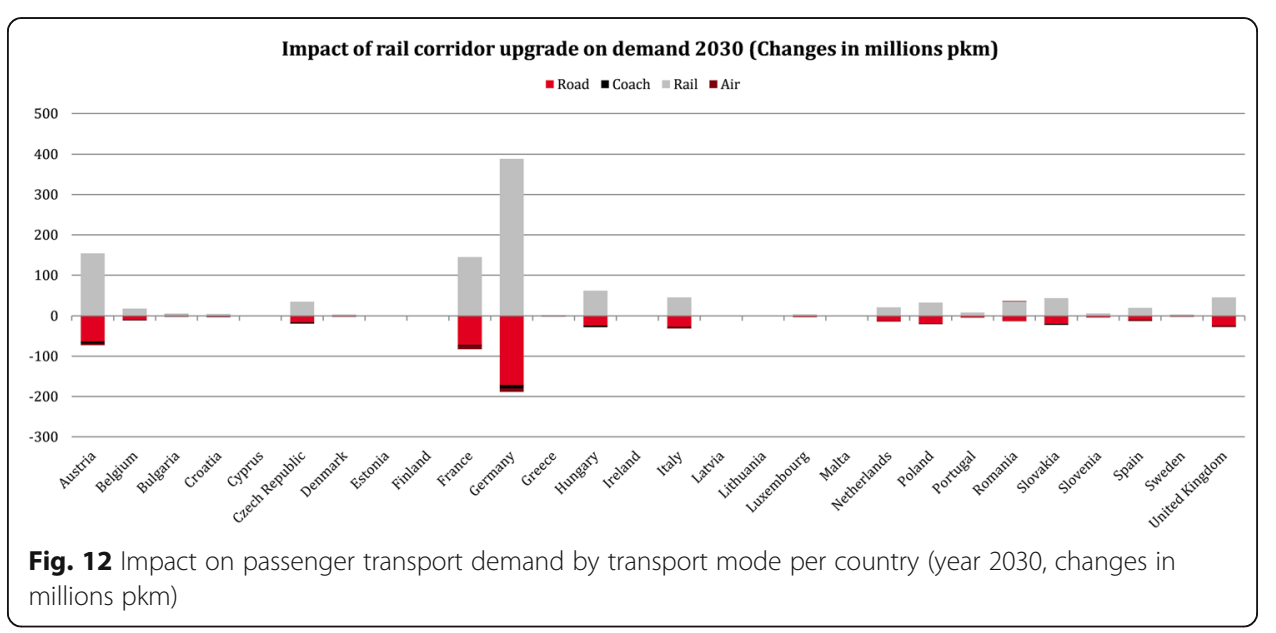


Table 6 Case study - Impact on emissions and fuel consumption p.a. (in tons), EU28 + 2, difference Scenario-Baseline

\begin{tabular}{llllll}
\hline Year & Fuel consumption & CO2 & NOx & PM & SO2 \\
\hline 2030 & -9963 & $-35,105$ & -54 & -3 & -1 \\
2035 & -9411 & $-33,449$ & -60 & -3 & 0 \\
2040 & -9956 & $-34,320$ & -62 & -3 & 0 \\
2045 & $-10,253$ & $-35,044$ & -65 & -3 & -1 \\
2050 & -8934 & $-31,284$ & -62 & -3 & -1 \\
\hline
\end{tabular}

Also the existence of the EU Reference Scenario, which outlines long-term projections until 2050 and covers aspects such as transport demand, energy consumption and vehicle fleet, was a substantial support for the calibration of the HIGH-TOOL model. On the other hand, it is becoming a broadly accepted view that there will be large structural changes in the (near) future in many economic sectors, also within transport and mobility (see e.g., Chen et al. 2016; Brynjolfsson and McAfee 2014; Blasi et al. 2013). The National Research Council of the USA (2010) states: "All forecasting methodologies depend to some degree on the inspection of historical data. However, exclusive reliance on historical data inevitably leads to an overemphasis on evolutionary innovation and leaves the user vulnerable to surprise from rapid or nonlinear developments. [...] A methodology that can forecast disruptive technologies must overcome the evolutionary bias and be capable of identifying unprecedented change". Also the currently instable political and geo-political situation in many world regions, wars and migration cause a high level of uncertainty in terms of future development of demographic, social, societal and socio-economic patterns which substantially influence transport demand. However, the official national and EU forecasts currently tend to suffer from a lack of adapted methodology to be able to anticipate for the future in which direct and indirect impacts of disruptive technologies will play a major role. Thus, further research is needed to develop a generally accepted, trusted, transparent and repeatable approach that does not solely rely on historical developments, but which allows to deal with breaks in trends and derived developments.

The current version of the HIGH-TOOL model offers various possibilities for further developments: for instance, enhancing the zoning system of transport demand modelling from the spatial level of NUTS-2 to NUTS-3 will significantly reduce the share of intra-zonal transport demand and increase the accuracy of transport demand modelling. Also, a closer link to a network-based model, which goes beyond the currently implemented hypernet approach for passenger transport, will enhance the tool's scope of

Table 7 Case study - Impact on road accidents p.a. (number of injured persons), EU28 + 2, difference Scenario-Baseline

\begin{tabular}{lll}
\hline Year & Serious injuries & Slight injuries \\
\hline 2030 & -9 & -67 \\
2035 & -5 & -77 \\
2040 & -9 & -69 \\
2045 & -11 & -82 \\
2050 & -8 & -73 \\
\hline
\end{tabular}


Table 8 Case study - Impact on Gross Value Added by sector p.a. (million €), EU28 + 2, difference Scenario-Baseline

\begin{tabular}{llll}
\hline Year & Primary & Secondary & Tertiary \\
\hline 2030 & 0 & 0 & 0 \\
2035 & 0.1 & 6.5 & 3.7 \\
2040 & 0.1 & 7.0 & 4.1 \\
2045 & 0.2 & 7.3 & 4.4 \\
2050 & 0.1 & 7.4 & 4.6 \\
\hline
\end{tabular}

application and improve the spatial representation of infrastructure-related policies. Increasing the regional level of detail of traffic cells and connecting the HIGH-TOOL model with a network-based model however, imply unfavourable impacts on model run time, which needs to be avoided as far as possible by smart data handling and processing methodology.

In combination with an enhanced approach to model network effects of transport policies, a dedicated transport supply module could be implemented to consolidate the representation of the supply side (including the operationalization of policies) in one entity.

Moreover, the increasing relevance of Sharing Economy concepts in transport (e.g., car/bike sharing; ride sharing) calls for a more sophisticated and explicit consideration of these schemes by transport demand and policy assessment tools.

Further mega trends in transport are electrification and autonomous driving. The electrification of the road transport sector indicates the requirement to connect transport demand and energy modelling more closely, in order to obtain a better understanding of interdependencies between these sectors and to explore the potential of electrification of transport for decentral energy supply concepts (e.g., by using electric vehicles as mobile energy storage). Autonomous driving will result in tremendous impacts on the transport sector by enhancing access to mobility, improve safety, and add the potential to alleviate congestion, reduce travel time and reduce environmental impacts (see e.g., Harper et al. 2016; Fagnant and Kockelman 2014; Hars 2014). Though it remains unclear how much of the potential benefits will actually be exploited, since vehicle mileage is expected to increase (Szimba and Orschiedt 2017). Supported by further research on travel behaviour, traffic engineering and the scope of business models expected from autonomous driving, an extended version of the HIGH-TOOL model could be used to estimate the impacts of autonomous driving at European scale.

Finally, the consideration of future modes of transport such as drones or the Hyperloop concept may provide avenues for model enhancement.

With its high degree of openness and its modular structure, the HIGH-TOOL model provides the basis for an efficient further development of the model in the indicated directions and beyond, and thus lays the foundation for further innovations in the realm of assessment of transport policies and mobility concepts.

\section{Endnotes}

${ }^{1}$ NUTS: Nomenclature of Units for Territorial Statistics 


\section{Abbreviations}

AngularJS: A client framework to build web applications in JavaScript; BAU: Business as usual; CEF: Connecting Europe Facility; $\mathrm{CO}_{2}$ : Carbon Dioxide; DEM: Demography module of the HIGH-TOOL model; DV: Deterrence Value; ECR: Economy \& Resources module of the HIGH-TOOL model; EMC: Expected Minimum Cost; ENV: Environment module of the HIGH-TOOL model; ERSAP: European Road Safety Action Program; EU Ref: EU Reference Scenario 2013; EU: European Union; EU28 + 2: 28 Member States of the European Union plus Norway and Switzerland; EU28: 28 Member States of the European Union; Eurostat: Statistical Office of the European Union; FRD: Freight Demand module of the HIGH-TOOL model; GDP: Gross Domestic Product; Gpkm: Giga passenger-kilometer; GVA: Gross Value Added; HDV: Heavy Duty Vehicle; LDV: Light Duty Vehicle; NOx: Nitric oxide and nitrogen dioxide; NST: Eurostat's Standard Goods Classification for Transport Statistics; NUTS: Nomenclature of Territorial Units for Statistics; A number assigned to it defines the level of granularity, such as 0 for the country level; O/D: Origin/ Destination; P/C: Production/ Consumption; PAD: Passenger Demand module of the HIGH-TOOL model; PostGIS: An open source software program that adds support for geographic objects to the PostgreSQL object-relational database; PostgreSQL: An objectrelational database; RTD: Research and Development; SAF: Safety module of the HIGH-TOOL model; Sails.js: A server framework to build Node.js applications; SOx: Sulfur oxide; TEN-T: Trans-European Networks for Transport; TPM: Transport Policy Measures

\section{Acknowledgements}

The authors would like to thank Hettie Boonman, Tina Laparidou and Cristian Lorenzo Martínez for their dedication for contributing to the development of the tool. The authors are also grateful to the anonymous reviewers for their valuable comments and suggestions to improve the quality of the paper.

\section{Funding}

The research has received funding from the European Union's Seventh Framework Programme for research, technological development and demonstration under grant agreement no 321624.

\section{Availability of data and materials}

The (co-)author(s) declare that the tool presented in this paper (and the involved data) is publicly available and can be requested from the HIGH-TOOL homepage (www.high-tool.eu).

\section{Declaration}

I confirm that I have read SpringerOpen's guidance on competing interests and have included a statement indicating that none of the authors have any competing interests in the manuscript.

\section{Authors' contributions}

All authors have contributed to the conception and design of the presented model, the development of the tool and involved data collection, analysis and interpretation. Under coordination by the corresponding author, all authors have been involved in the drafting of the article, and the critical revision of the paper. All authors have approved the version to be published.

\section{Competing interests}

The authors declare that they have no competing interests.

\section{Publisher's Note}

Springer Nature remains neutral with regard to jurisdictional claims in published maps and institutional affiliations.

\section{Author details}

${ }^{1}$ Karlsruhe Institute of Technology (KIT), Network Economics, Institute of Economics (ECON), Waldhornstr. 27, Bldg. 01.96, 76131 Karlsruhe, Germany. ${ }^{2}$ Karlsruhe Institute of Technology (KIT), Karlsruhe, Germany. ${ }^{3}$ Netherlands

Organisation for Applied Scientific Research TNO, The Hague, The Netherlands. ${ }^{4}$ Panteia, Zoetermeer, The Netherlands. ${ }^{5}$ MKmetric Gesellschaft für Systemplanung mbH, Karlsruhe, Germany. ${ }^{6}$ MCRIT S.L., Barcelona, Spain. ${ }^{7}$ Transport \& Mobility Leuven NV (TML), Leuven, Belgium. ${ }^{8}$ Significance, The Hague, The Netherlands. ${ }^{9}$ Fómterv, Budapest, Hungary.

${ }^{10}$ E-mergo, Delft, The Netherlands.

Received: 15 January 2018 Accepted: 14 October 2018

Published online: 25 October 2018

\section{References}

Blasi J, Freeman R, Kruse D (2013) The citizens share, reducing inequality in the 21st century. Yale University Press, New Haven \& London

Brynjolfsson E, McAfee A (2014) The second machine age. W.W. Norton \& Company, New York

Burgess A, Chen T, Snelder M, Schneekloth N, Korzhenevych A, Szimba E, Kraft M, Krail M, Nielsen O, Hansen C, Martino A, Fiorello D, Christidis R (2008) Final report TRANS-TOOLS. In: deliverable D6. Funded by the 6th framework RTD Programme, Delft. Available under http://www.transport-research.info/sites/default/files/project/documents/20100304_ 172116_94411_TRANSTOOLS\%20-\%20Final\%20Report.pdf Accessed 08 May 2018

Cascetta E, Coppola P (2013) High speed rail (HSR) induced demand models. Procedia - Soc Behav Sci 111:147-156

Chen M, Bodea G, Huijboom N (2016) Anticipating EU transport sector governance. Paper presented at FORMForum 2016, Brussels

De Ceuster G, van Herbruggen B, Ivanova O, Carlier K, Martino A, Fiorello D (2007) TREMOVE: service contract for the further development and application of the transport and environmental TREMOVE model. Transport and Mobility Leuven. 
Available under http://www.tmleuven.be/methode/tremove/Final_Report_TREMOVE_9July2007c.pdf Accessed 08 May 2018

De Jong G, Daly AJ, Pieters M, van der Hoorn T (2007) The logsum of an evaluation measure: review of the literature and new results. Transp Res A 41:874-889

Delhaye E, Akkermans L, De Ceuster G, Vanhove F, Bosetti S (2010) Lot 2 Impact Assessments and Evaluations in the field of transport. The preparation of the European Road Safety Action Program 2011-2020. Not publicly available

European Commission (2009) Impact Assessment Guidelines SEC(2009) 92. Available under. http://ec.europa.eu/smartregulation/impact/commission_guidelines/docs/iag_2009_en.pdf. Accessed 8 May 2018

European Commission (2011a) Roadmap to a Single European Transport Area - Towards a competitive and resource efficient transport system COM(2011) 144 final. Available under http://eur-lex.europa.eu/legal-content/EN/TXT/PDF/?uri=CELEX: 52011DC0144\&from=EN. Accessed 08 May 2018.

European Commission (2011b) The 2012 Ageing Report: Underlying Assumptions and Projection Methodologies. Eur Econ 4(2011). https://doi.org/10.2765/15373

European Commission (2013) EU energy, transport and GHG emissions trends to 2050. Reference scenario 2013. Available under https://ec.europa.eu/transport/sites/transport/files/media/publications/doc/trends-to-2050-update-2013.pdf Accessed 08 May 2018.

European Union (2013) REGULATION (EU) No 1316/2013 OF THE EUROPEAN PARLIAMENT AND OF THE COUNCIL of 11 December 2013 establishing the Connecting Europe Facility, amending Regulation (EU) No 913/2010 and repealing Regulations (EC) No 680/2007 and (EC) No 67/2010. https://eur-lex.europa.eu/legal-content/EN/TXT/PDF/?uri=CELEX: 32013R1316\&from=EN Accessed 08 May 2018.

Fagnant DJ, Kockelman KM (2014) The travel and environmental implications of shared autonomous vehicles, using agentbased model scenarios. Transp Res Part C: Emerging Technologies 40(2014):1-13

Harper CD, Hendrickson CT, Mangones S, Samaras C (2016) Estimating potential increases in travel with autonomous vehicles for the non-driving, elderly and people with travel-restrictive medical conditions. Transp Res Part C: Emerging Technologies 72:1-9. https://doi.org/10.1016/.ttr. 2016.09.003

Hars A (2014) Wie revolutionär sind selbstfahrende Fahrzeuge - eine Wirkungskettenanalyse. In: Proff H (ed) Radikale Innovationen in der Mobilität - Technische und betriebswirtschaftliche Aspekte. Springer Gabler, Wiesbaden

Ivanova O (2014) Modelling inter-regional freight demand with input-output, gravity and SCGE methodologies. In: Modelling freight transport 2014, pp 13-42. https://doi.org/10.1016/B978-0-12-410400-6.00002-1

Ivanova O, Kancs A, Stelder D (2011) Modelling inter-regional trade flows: data and methodological issues in Rhomolo. ERSA conference papers, ersa10p500

IWW, SMA, Wien TU (2001) Magistrale für Europa, Schlussbericht. Cofounded by the European Commission under the INTERREG II C programme, Karlsruhe

Kiel J, Laparidou K, Smith R, van Meijeren J, Chahim M, Szimba E, Kraft M, Ihrig J, Mandel B, Berki Z, Székely A, Purwanto J, Corthout R, Larrea E, van Grol R, de Bok M (2016b) Validating the HIGH-TOOL Model: results of checks and implemented case studies. In: HIGH-TOOL Deliverable D8.2. project co-funded by the European Commission under the 7th Framework Programme, Zoetermeer, Karlsruhe Available under http://www.high-tool.eu/public_content/downloads/HT_D_8_2_v1_1. pdf Accessed 08 May 2018

Kiel J, Smith R, Laparidou K (2016a) Documentation: Updated Input Database for the HIGH-TOOL Model, HIGH-TOOL Deliverable D3.2. project co-funded by the European Commission under the 7th Framework Programme, Zoetermeer/ Karlsruhe Available under http://www.high-tool.eu/public_content/downloads/HT_D_3_2_v1_1.pdf Accessed 05 September 2018

Mandel B, Kraft M, Schnell O, Klar R, Ihrig J, Szimba E, Smith R, Laparidou K, Chahim M, Corthout R, Purwanto J (2016) Final Structure of the HIGH-TOOL Model. In: HIGH-TOOL Deliverable D2.2. project co-funded by the European Commission under the 7th Framework Programme, Karlsruhe Available under http://www.high-tool.eu/public_content/downloads/ HT_D_2_2_v1_2.pdf Accessed 08 May 2018

McIntosh BS, Ascough IIJC, Twery M, Chew J, Elmahdi A, Haase D, Harou J, Hepting D, Cuddy S, Jakeman AJ, Chen S, Kassahun A, Lautenbach S, Matthews K, Merritt W, Quinn NWT, Rodriguez-Rodan I, Sieber S, Stavenga M, Sulis A, Ticehurst J, Volk M, Wrobel M, van Delden H, El-Sawah S, Rizzoli A, Voinov A (2011) Environmental decision support systems (EDSS) development - challenges and best practices. Environ Model Softw 26(12):1389-1402

National Research Council (2010) Persistent forecasting of disruptive technologies. The. National Academies Press, Washington, DC. https://doi.org/10.17226/12557

NEA (2007) TRANSTOOLS - Mode Split Model, Revisions for TRANSTOOLS Version, vol 1, p 3

Newton S, Kawabata Y, Smith R (2015) NEAC 10. Modelling Description 2015. Panteia, Zoetermeer

Nilsson M, Jordan A, Turnpenny J, Hertin J, Nykvist B, Russel D (2008) The use and non-use of policy appraisal tools in public policy making: an analysis of three European countries and the European Union. Policy Science 41:335-355. https://doi. org/10.1007/s11077-008-9071-1

Ortúzar JD, Willumsen LG (2011) Modelling transport, 4th edn. John Wiley \& Sons Ltd, Chichester

Papadimitrio G, Ntziachristos L, Wüthrich P, Notter B, Keller M, Fridell E, Winnes H, Styhre L, Sjödin A (2013) Transport data collection supporting the quantitative analysis of measures relating to transport and climate change Project acronym: TRACCS. Available under http://emisia.com/sites/default/files/TRACCS_Final.pdf Accessed 08 May 2018

Sieber S, Amjath-Babu TS, BS MI, Tscherning K, Müller K, Helming K, Pohle D, Fricke K, Verweij P, Pacini C, Jansson T, Gomez y Paloma S (2013) Evaluating the characteristics of a non-standardised Model Requirements Analysis (MRA) for the development of policy impact assessment tools. Environ Model Softw 49:53-63. https://doi.org/10.1016/..envsoft.2013.07.007

Szimba E (2016) Final Report, HIGH-TOOL. In: Deliverable D10.5. Project co-funded by the European Commission under the 7th Framework Programme, Karlsruhe Available under http://www.high-tool.eu/public_content/downloads/HT_Final_ Report.pdf Accessed 08 May 2018

Szimba E, Ihrig J, Kraft M, Schimke A, Schnell O, Newton S, Kawabata J, Versteegh R, Smith R, van Meijeren J, Jin-Xue H, de Stasio C, Fermi F, Breemersch T (2013) ETISplus Database - Content and Methodology. Deliverable D6 of ETISplus (European transport information system). Report financed by the European Commission (7th RTD Programme), Zoetermeer Available under http://www.tmleuven.be/project/etisplus/01-D6-Final-V1.3-CH1-2-3\%20W97.pdf Accessed 08 May 2018 
Szimba E, Mandel B, Kraft M, Ihrig J (2017) A decision support tool for the strategic assessment of transport policies structure of the tool and key features. Transp Res Procedia 25:2843-2860. https://doi.org/10.1016/j.trpro.2017.05.262

Szimba E, Orschiedt $Y$ (2017) How beneficial is fully automated driving in urban areas from a socio-economic point of view? Proceedings of the conference Future City 2017: urban sustainable development and mobility. University of Transport and Communications, Hanoi

United Nations (2014) UN world population prospects. Available under http://esa.un.org/unpd/wpp/. Accessed 08 May 2018

Van Grol R, De Bok M, De Jong G, Van Eck G, Ihrig J, Kraft M, Szimba E, Mandel B, Ivanova O, Corthout R, Purwanto J, Smith R, Laparidou K, Helder E, Grebe S, Székely A (2016b) Elasticities and Equations of the HIGH-TOOL model (Final Version). In: HIGH-TOOL Deliverable D4.3. Project co-funded by the European Commission under the 7th Framework Programme, Karlsruhe Available under http://www.high-tool.eu/public_content/downloads/HT_D_4_3_v1_2.pdf Accessed 08 May 2018

van Meijeren J, Davydenko I, Chahim M, Szimba E, Kraft M, Ihrig J, Smith R, Laparidou T, Purwanto J, Corthout R (2016) Validation by Coherence Checks, HIGH-TOOL Deliverable D8.1, project co-funded by the European Commission under the 7th Framework Programme, Karlsruhe

Vickerman R (1996) High-speed rail in Europe: experience and issues for future development. Ann Reg Sci 31(1):21-38. https://doi.org/10.1007/s001680050037

Wood R, Stadler K, Bulavskaya T, Lutter S, Giljum S, de Koning A, Kuenen J, Schütz H, Acosta-Fernández J, Usubiaga A, Simas M, Ivanova O, Weinzettel J, Schmidt JH, Merciai S, Tukker A (2015) Global sustainability accounting-developing EXIOBASE for multi-regional footprint analysis. Sustainability 7(1):138-163. https://doi.org/10.3390/su7010138

Submit your manuscript to a SpringerOpen ${ }^{\circ}$ journal and benefit from:

- Convenient online submission

- Rigorous peer review

- Open access: articles freely available online

- High visibility within the field

- Retaining the copyright to your article

Submit your next manuscript at $>$ springeropen.com 